\title{
Processing of primary and secondary rewards: a quantitative meta-analysis and review of human functional neuroimaging studies
}

Guillaume Sescousse ${ }^{1,2}$, Xavier Caldú ${ }^{1,3}$, Bàrbara Segura ${ }^{1,4}$ and Jean-Claude Dreher ${ }^{1}$

${ }^{1}$ Reward and decision making team, Cognitive Neuroscience Centre, CNRS, 67 Bd Pinel, 69675 Bron, France

${ }^{2}$ Current address: Radboud University Nijmegen, Donders Institute for Brain, Cognition, and Behaviour, Centre for Cognitive Neuroimaging, 6500 HB, Nijmegen, The Netherlands

${ }^{3}$ Current address: Department of Psychiatry and Clinical Psychobiology, Faculty of Psychology, University of Barcelona, Barcelona, Spain

${ }^{4}$ Current address: Department of Psychiatry and Clinical Psychobiology, Faculty of Medicine, University of Barcelona, Barcelona, Spain

Corresponding author:

Jean-Claude Dreher, PhD

CNRS, Reward and decision-making team

Cognitive Neuroscience Center

67 Bd Pinel, 69675 Bron

France

Email: dreher@isc.cnrs.fr

Tel: +33 (0)4 37911238 


\begin{abstract}
One fundamental question concerning brain reward mechanisms is to determine how reward-related activity is influenced by the nature of rewards. Here, we review the neuroimaging literature and explicitly assess to what extent the representations of primary and secondary rewards overlap in the human brain. To achieve this goal, we performed an Activation Likelihood Estimation meta-analysis of 87 studies (1452 subjects) comparing the brain responses to monetary, erotic and food reward outcomes. Those three rewards robustly engaged a common brain network including the ventromedial prefrontal cortex, ventral striatum, amygdala, anterior insula and mediodorsal thalamus, although with some variations in the intensity and location of peak activity. Money-specific responses were further observed in the most anterior portion of the orbitofrontal cortex, supporting the idea that abstract secondary rewards are represented in evolutionary more recent brain regions. In contrast, food and erotic (i.e. primary) rewards were more strongly represented in the anterior insula, while erotic stimuli elicited particularly robust responses in the amygdala. Together, these results indicate that the computation of experienced reward value does not only recruit a core "reward system" but also reward type-dependent brain structures.
\end{abstract}

Keywords: reward processing; meta-analysis; experienced value; reward outcome; monetary reward; food reward; erotic reward; fMRI; neuroimaging; ventral striatum; orbitofrontal cortex; anterior insula 


\section{Introduction}

Much of our daily life is driven by the prospect of rewards. A classical distinction concerns primary rewards -i.e. food, sex and shelter- and secondary rewards -such as money or power. In contrast to primary rewards which have an innate value and are essential for the maintenance of homeostasis and reproduction, secondary rewards are not directly related to survival and only gain value through learned association with lower-level rewards. A long-standing question is whether primary and secondary rewards are processed in common and/or distinct brain structures (Schultz, 2000). Due to their evolutionary differences, it is tempting to speculate that primary and secondary rewards may be represented in phylogenetically distinct brain regions (Knutson and Bossaerts, 2007), but the evidence remains scarce. In contrast, animal research provides empirical evidence for a centralized processing of reward in the brain, based on a wealth of studies showing that a core set of brain regions -including the ventral tegmental area, nucleus accumbens, amygdala and ventromedial prefrontal cortex- are sensitive to various types of rewards (Berridge, 2003; Hikosaka et al., 2008; Schultz, 2006). However, studies in animals use a very limited number of primary rewards (e.g. food and juice), which hinders the generalizability of the results to more abstract secondary rewards. Furthermore, investigation techniques such as electrophysiology and focal brain lesions used in animals typically focus on specific brain structures and do not offer a "full picture" at the brain system level. Neuroimaging appears as an ideal tool to overcome these limitations, since it allows to visualize cerebral activity throughout the whole brain, and can be easily used in humans in order to compare secondary versus primary rewards.

Building on this opportunity, recent studies in decision neuroscience and neuroeconomics have investigated how the brain represents reward value while deciding between different goods. Such a choice is assumed to rely on the computation of a "decision value", allowing the comparison of various reward prospects on a common scale. Several studies have demonstrated that this computation is performed in the ventromedial prefrontal 
cortex (vmPFC) and ventral striatum regardless of the goods at stake, providing compelling evidence in favour of a "common reward currency" (Chib et al., 2009; Hare et al., 2008; Knutson et al., 2007; FitzGerald et al., 2009; Plassmann et al., 2007; see also Peters and Buchel, 2010 for a review). Yet, these neuroeconomic approaches focus on subjective value as inferred from choices, and only a handful of neuroimaging studies have made similar direct comparisons concerning the "experienced value" of rewards, computed at the time of outcome (Izuma et al., 2008; Rademacher et al., 2010; Sescousse et al., 2010; Smith et al., 2010; Grabenhorst et al., 2010a). Moreover, although the ventral striatum and vmPFC tend to emerge as prime candidates for computing experienced values, the results of these studies are rather heterogeneous and general conclusions are difficult to draw. Alternatively, insights can be gleaned from reviews synthesizing the results of single reward studies. Several of them have been published in the past years, and concur on including the striatum, dopaminergic midbrain, amygdala and orbitofrontal cortex in a "common reward circuit". However, most of these reviews are qualitative and hence suffer from some degree of subjectivity: only evidence supporting the involvement of the above regions is presented, and is not critically weighed against all the studies not reporting similar evidence (Haber and Knutson, 2010; O'Doherty, 2004; McClure et al., 2004b). Addressing this issue, a few quantitative meta-analyses published in recent years have provided a more objective overview of the human neuroimaging literature. However, those meta-analyses were either pooling different reward types together (Liu et al., 2011; Cauda et al., 2011; Kuhn and Gallinat, 2012) or focusing on a single reward type (e.g. monetary rewards: Knutson and Greer, 2008; erotic rewards: Kuhn and Gallinat, 2011; Stoleru et al., 2012).

To deepen our understanding of the functional architecture of reward processing in the brain, it is crucial to evaluate the consistency and specificity of reward-related activations across different types of rewards. To achieve this goal, we propose to perform an activation likelihood estimation (ALE) meta-analysis of the neuroimaging literature on reward processing. This approach has several features which make it well-suited to address some of the previous concerns (Laird et al., 2005; Wager et al., 2009). First, ALE provides a 
quantitative measure of cross-study consistency. In contrast to label-based reviews which start from anatomical labels and draw conclusions based on the clustering of these labels, ALE is a voxel-based approach which uses stereotaxic coordinates as input, performs analyses on their spatial distribution, and then only derives anatomical labels based on the resultant clusters. This confers high objectivity to this method, which is immune to risks of incongruent or erroneous labelling among the selected studies. Moreover, ALE produces statistically defensible conclusions, by using numerical estimates (ALE statistics) and significance thresholds to measure the degree of agreement between studies. Importantly, ALE is able to make comparisons between meta-analyses, similar to contrasts between conditions in individual studies. This feature can be used to investigate specificity, e.g. by subtracting activations related to different reward types.

Besides providing a synthetic overview of the literature, the use of a quantitative meta-analytic approach also has practical benefits. For instance, many studies restrict their analyses to regions of interest (ROIs), based on the alleged role of these regions in reward processing. However, this kind of assumption concerning structure-function relationships should be ideally based on an objective meta-analysis. Moreover, for functionally defined brain regions such as the ventral striatum or medial OFC, current label-based reviews (e.g. Delgado, 2007; Haber and Knutson, 2010; Noonan et al., 2012) do not provide average stereotaxic coordinates from which to derive ROIs. As a consequence, a common practice for anatomically constrained analyses is to build ROIs based on the coordinates extracted from a particular study, which by definition is not representative of the literature. A quantitative meta-analysis would bring a simple solution to these issues.

To investigate the consistency and specificity of reward-related responses in the brain, we compared three types of reward outcomes: monetary gains, pleasant foods and visual erotic stimuli. These rewards were chosen because they are widely used by humans and are also the most studied in the neuroimaging literature, therefore ensuring a sufficient number of activation foci to conduct our meta-analyses. We first assessed the consistency of brain activations elicited by each reward independently, and we then investigated the 
consistency and specificity of these meta-analytic results across the three selected rewards by performing conjunction and contrast analyses. Specific details regarding study selection and analytic procedures are provided below.

\section{Methods}

\subsection{Selection of studies}

We conducted three independent searches in PubMed in order to identify fMRI and Positron Emission Tomography (PET) studies dealing with the processing of monetary, erotic and food reward outcomes. Each search used a combination of key words referring to the type of reward (i.e. [("money" OR "monetary" OR "financial") AND ("reward")]; [("food" OR "taste" OR "juice") AND ("reward" OR "pleasant")]; [("erotic" OR "sexual") AND ("stimuli")]) and to the investigation technique (i.e. ["fMRI" OR "PET" OR "neuroimaging"]). These searches retrieved 242, 138 and 66 studies, respectively (July 2010). The lists of references cited in these studies were also scrutinized and relevant studies incorporated to our pool. One unpublished study from our laboratory, manipulating food and erotic rewards, was further added (Domenech and Dreher, 2008). Each article was then carefully read by at least two of the authors to make sure that it fulfilled the following selection criteria:

1) Only studies reporting whole-brain results were included. Indeed, in order to provide an objective view of reward processing in the brain, it is important to make sure that all cerebral regions have an equal chance of being represented, by specifically excluding studies reporting partial (and inherently biased) results. In particular, we excluded studies entirely based on ROI analyses, studies without a full-brain coverage, and PET studies using selective radiotracers other than $\mathrm{H}_{2}{ }^{15} \mathrm{O}$.

2) Because the ALE approach is based on activation foci, only studies reporting spatial coordinates in a standardized stereotaxic space were included. Talairach coordinates were transformed to $\mathrm{MNI}$ space using the Lancaster transform implemented in the 
GingerALE software (see below). In case of doubt about the coordinate system used, ambiguity was resolved by writing to the authors.

3) Since brain activity in reward-related regions is known to be sensitive to age (Dreher et al., 2008b), as well as to various types of pharmacological manipulations (Nestler, 2005), we only included results obtained in healthy, drug-free, adult subjects. Moreover, we excluded studies with a particularly low sensitivity, i.e. based on fewer than six subjects.

4) Regardless of the protocol used, included studies had to involve the delivery of a pleasant stimulus. Moreover, the results had to unambiguously reflect reward processing at the time of outcome, i.e. they had to be based on contrasts such as "reward > control condition", "reward > omission of reward", "reward > punishment" or "correlation with reward intensity". In particular, studies focusing on reward anticipation or the computation of decision values were excluded, as well as contrasts investigating specific questions such as prediction errors, sexual preference or sensory-specific satiation. Food reward studies systematically involved the delivery of real food/juice in the mouth, while all erotic reward studies involved the presentation of pictures or movies featuring sexually explicit content. All these studies further reported behavioural ratings (assessing pleasantness, arousal or motivation) showing that the stimuli used were indeed rewarding to the participants.

5) In case of multiple studies based on the same dataset, only one of them was included. Moreover, only one contrast per study was selected. Almost all included foci survived a statistical threshold corrected for multiple comparisons or an uncorrected p-value threshold of $p<0.001$ (see Tables 1, 2 and 3 for details).

Following the implementation of these criteria, there remained 33 experiments (394 foci / 565 subjects) on monetary rewards, 26 experiments (469 foci / 443 subjects) on erotic rewards and 28 experiments (318 foci / 444 subjects) on food rewards (Tables 1, 2 and 3). 


\subsection{Data analysis}

Analyses were performed using the revised ALE method as implemented in the latest version of the GingerALE software (version 2.2, http://brainmap.org/ale), (Turkeltaub et al., 2002; Eickhoff et al., 2009). While the original implementation of the ALE method used a fixed-effects procedure testing for a clustering between foci (Laird et al., 2005), it was recently modified so as to offer a random-effects approach assessing clustering between experiments (Eickhoff et al., 2009; Eickhoff et al., 2012).

The ALE method starts by modelling each activation focus reported for a given experiment as the centre of a 3D Gaussian probability distribution. The width of this distribution, reflecting spatial uncertainty, is derived from an empirical model and weighted by the sample size of each experiment (Eickhoff et al., 2009). Then, a modelled activation (MA) map is computed for each experiment by combining the probability distributions of all foci. The union of these MA maps across experiments yields voxel-wise ALE scores, describing the convergence of results at each particular location of the brain. This convergence between experiments is then compared to a random convergence (i.e. noise) in order to make spatial inferences. Specifically, experimental ALE scores are compared to an analytically derived null-distribution reflecting a random spatial association between experiments (Eickhoff et al., 2012). Importantly, this procedure is akin to a random-effects analysis. The statistical significance of the resulting $p$-values is determined using a false discovery rate (FDR) corrected threshold, which is applied to the ALE map along with a minimum cluster size. This procedure was first employed to perform three independent meta-analyses aimed to identify the brain regions consistently activated by monetary, food and erotic rewards. We employed an FDR-corrected threshold of $\mathrm{p}<0.01$ and a minimum cluster size of $600 \mathrm{~mm}^{3}$.

We then performed contrast meta-analyses between these rewards. First, the ALE maps corresponding to two rewards were subtracted on a voxel-by-voxel basis. Then, the studies associated with these two rewards were pooled together and randomly divided into two groups of the same size as the two original sets of studies reflecting the contrast ALE 
analysis. ALE scores for these two randomly assembled groups were calculated and the difference between these ALE scores was recorded for each voxel. This procedure was then repeated for 5000 permutations of randomly assembled studies, yielding a null-distribution of ALE score differences in each voxel. Random-effects inference was achieved by comparing this null-distribution voxel-by-voxel with the experimental ALE score differences. Based on this approach, we compared monetary versus erotic rewards, monetary versus food rewards, and erotic versus food rewards. We employed an FDR-corrected threshold of $p<0.05$, along with a minimum cluster size of $600 \mathrm{~mm}^{3}$ (a less stringent $p$-value was used because contrast analyses are more conservative). This resulted in six contrast maps, which were further binarized and combined to identify "reward type-specific" regions. "Money-specific" regions were defined as those stemming from the conjunction of money>erotic and money>food maps, "erotic-specific" regions were defined as those stemming from the conjunction of erotic>money and erotic $>$ food maps, and "food-specific" regions were defined as those stemming from the conjunction of food>erotic and food>money maps. In addition, "primary reward-specific" regions were defined as those stemming from the conjunction of erotic $>$ money and food>money maps.

Anatomical localization of functional clusters was performed with the Talairach Daemon application (Lancaster et al., 2000) and a probabilistic atlas (Hammers et al., 2003). For visualization purposes, statistical output maps were overlaid on the Colin brain provided with GingerALE, using the Mango software (www.ric.uthscsa.edu/mango).

\section{Results}

The first goal of this study was to identify a "common reward circuit" as defined by the regions of overlap between monetary, food and erotic reward outcomes. The results of the meta-analyses conducted separately for each reward are illustrated in Figure 1, as well as the resulting overlaps. They show that a set of brain regions was consistently recruited by all 
three rewards, although with varying levels of significance and spatial extent. These regions included the bilateral striatum, mostly in its ventral part, the bilateral anterior insula/frontal operculum, the mediodorsal thalamus, the bilateral amygdala and the ventromedial prefrontal cortex (VmPFC) extending into the pregenual anterior cingulate cortex (pgACC). Fully detailed results are reported in Supplementary Tables 1, 2 and 3.

Moreover, we performed statistical comparisons between studies, in order to identify brain regions responding more robustly to one reward relative to the other two (Fig. 2). The results showed that the bilateral ventral striatum and the right anterior OFC were more likely to be activated by monetary compared to food and erotic rewards. In contrast, the dorsal anterior insula and the somatosensory cortex appeared more likely to be activated by food compared to monetary and erotic rewards. Finally, the bilateral amygdala, the ventral anterior insula and the extrastriate body area were more robustly activated by erotic than by monetary and food rewards. The only brain area more reliably activated by primary (i.e. erotic and food) compared to secondary (i.e. monetary) rewards was located in the middle insula.

Perhaps surprisingly at first sight, one may note that among "reward type-specific" regions, defined as those more reliably activated by one reward compared to the other two, some of them were also part of the "common reward circuit". This result simply illustrates the fact that, despite being recruited by several rewards, some regions were still more reliably activated by one of them in particular. Moreover, in order to ensure that our results were not biased by potential false positives resulting from the most liberal statistical thresholds used in some studies, we ran the above analyses again only including the most conservative studies (i.e. those in which the statistical threshold was explicitly corrected for multiple comparisons or was the combination of an uncorrected voxel-level threshold and a cluster-extent threshold; see Tables 1, 2 and 3). All the results presented in Figure 1 survived this more stringent procedure, confirming the robustness of our findings. 


\section{Discussion}

This meta-analysis provides a synthetic and objective overview of reward processing in the human brain, as provided by the paradigmatic examples of monetary, food and erotic rewards. As expected, the results confirmed the existence of a core set of brain regions processing reward outcomes in an indiscriminate fashion, in line with the idea of a centralized "reward circuit". In addition, comparative analyses between rewards revealed that some regions were more specifically recruited by one type of reward compared to the others. Below we discuss those results in the light of current views on the putative functional role of these regions, and offer some tentative explanations to account for the observed differences between rewards. The discussion is organized by cerebral region, so that the reader can easily navigate from one sub-section to another.

\subsection{Ventral striatum}

\subsubsection{Modality-independent activations}

The striatum, essentially in its ventral part, was found to be consistently activated by monetary, food and erotic outcomes in our meta-analysis. Many other rewards were found to elicit similar responses in the striatum, including beautiful faces (Aharon et al., 2001; Kampe et al., 2001), desirable objects (Erk et al., 2002), pleasant music (Menon and Levitin, 2005; Blood and Zatorre, 2001) or reputation and social hierarchy (Izuma et al., 2008; Zink et al., 2008). Importantly, recent studies using large-scale reverse inferences have suggested that the ventral striatum has a relatively specific role in reward processing, as compared to other cognitive processes (Cauda et al., 2011; Yarkoni et al., 2011).

Anatomically, the striatum is at the crossroads of several cortico-basal ganglia loops involved in limbic, associative and sensorimotor functions (Haber and Knutson, 2010). The ventral part, centred on the nucleus accumbens, is part of the limbic loop and receives many projections from the OFC, ACC, amygdala and midbrain. It is hence in an ideal place to 
integrate cognitive, motor and affective information and influence goal-directed behaviour independently of reward modality (Haber and Knutson, 2010; Delgado, 2007). Nonetheless, the precise computational function of the ventral striatum is the subject of a lively debate, which indirectly reflects the long-standing argument over the role of mesolimbic dopamine in reward processing (Berridge, 2007; Berridge and Robinson, 2003). A wealth of studies has shown that ventral striatal activity correlates with the intensity of received rewards, supporting a role in hedonic value representation (Smith et al., 2010; Izuma et al., 2008; Blood and Zatorre, 2001). However, reward value is intrinsically correlated with prediction error, a learning signal which measures the difference between received and expected rewards, and is used to update future predictions (Niv and Schoenbaum, 2008). Many fMRI studies have found brain responses consistent with such a reward prediction error in the ventral striatum (O'Doherty et al., 2004; Bray and O'Doherty, 2007; D'Ardenne et al., 2008). Besides, two studies that have explicitly tried to disentangle reward value from prediction error have reported a better correlation with the latter (Hare et al., 2008; Rohe et al., 2012). Interestingly, the ventral striatum has also been involved in the computation of aversive prediction errors (Delgado et al., 2008), and a recent study manipulating both rewards and punishments has proposed a more general account in terms of salient prediction error coding, regardless of reinforcer type or valence (Météreau and Dreher, 2012). Taken together, these studies suggest that the ventral striatal responses observed in our metaanalysis might reflect prediction error rather than reward value computation. This ambiguity in the interpretation illustrates the importance of distinguishing learning versus hedonic processes at the brain level, and points to the need for more sophisticated fMRI protocols able to separate them.

\subsubsection{Modality-dependent activations}

Our results indicate that monetary rewards activate the ventral striatum more reliably than do erotic and food rewards. However, we believe that this is unlikely to be related to the very nature of monetary rewards. Instead, we think that the present result stems from at least 
two important differences in how monetary and non-monetary rewards are usually delivered. First, the protocols used in monetary studies often involve learning of probabilistic stimulusreward associations, whereas most erotic and food studies use passive stimulation tasks with fully predictable rewards (see Table 1). Hence, following the hypothesis expressed in the previous paragraph, a possibility is that the differential activation observed in the ventral striatum results from a difference in prediction error computation. Supporting this idea, several studies show that erotic and food rewards elicit higher ventral striatal activity when they are unexpected compared to when they are expected (Sescousse et al., 2010; McClure et al., 2003; D'Ardenne et al., 2008; Veldhuizen et al., 2011). Another typical feature of monetary studies is the contingency between reward outcomes and motor action: in over $85 \%$ of the studies included in our meta-analysis, the delivery of monetary rewards was dependent on the participants' performance or decision, whereas such contingency was observed in very few (i.e. less than 10\%) of the food and erotic studies. Importantly, this form of instrumental conditioning was shown to elicit more robust striatal activations than passive reward delivery, supposedly by increasing the salience of pleasant outcomes (Zink et al., 2004; Tricomi et al., 2004; Elliott et al., 2004). This suggests that the differential activity presently observed in the ventral striatum might simply reflect a difference in terms of motor demands between monetary and non-monetary studies. Supporting this view, a previous study comparing monetary gains with erotic pictures delivered in the exact same context (i.e. involving identical motor demands) found virtually identical striatal activations in response to these two rewards (Sescousse et al., 2010).

Our results did not confirm a previous hypothesis suggesting that primary rewards such as juice might recruit more lateral portions of the striatum (i.e. the putamen) compared to secondary rewards such as money (Delgado, 2007). In contrast, we found that food- and erotic-related activations tended to cluster in the medial portion of the striatum and were less extended than money-related activations (see Fig. 1). This could be the sign of a territorialisation of reward processing in the striatum, and is in agreement with primate data 
showing enhanced sexual behaviour following local microinjection of a GABA receptor antagonist specifically in the medial part of the ventral striatum (Worbe et al., 2009).

\subsection{Ventromedial prefrontal / orbitofrontal cortex}

The orbitofrontal cortex is a vast and heterogeneous region, which can be broadly divided into three main sections based on anatomical and cytoarchitectonic considerations: a posterior OFC region, an anterior OFC region and a vmPFC region (Haber and Knutson, 2010). Our meta-analysis revealed different patterns of activation in these regions depending on reward type.

\subsubsection{Modality-independent activations in the vmPFC}

In concert with the ventral striatum, the vmPFC responded to all three tested rewards. Strongly connected to limbic regions including the amygdala, ventral striatum and hippocampus, this region is considered to play a central role in reward valuation. During reward anticipation, the vmPFC has been shown to be sensitive to various generic properties of rewards such as magnitude, probability or delay (Haber and Knutson, 2010). It has also found to be crucial in comparing the "goal values" of different rewards during decisionmaking (Rangel and Hare, 2010; Hare et al., 2009; Padoa-Schioppa and Assad, 2008). The present meta-analysis confirms that the vmPFC is equally important for the computation of experienced reward values. In fact, many studies using primary rewards have shown that brain activity in this region correlates with ratings of pleasantness, as confirmed in two recent meta-analyses (Peters and Buchel, 2010; Kuhn and Gallinat, 2012). Studies using monetary rewards have further demonstrated that vmPFC activity tracks the value of financial payoffs (O'Doherty et al., 2001a; Knutson et al., 2003). Importantly, the vmPFC seems to be sensitive to the subjective value of rewards rather than to their mere intensity. For instance, vmPFC activity decreases with satiety (O'Doherty et al., 2000; Small et al., 2001) and increases with personal preferences based on brand or price (Plassmann et al., 2008; 
McClure et al., 2004a). This indicates that the vmPFC is able to integrate value across different stimulus dimensions and different stimuli. One might further note that the activations observed in our meta-analysis spread over the pregenual ACC, which has strong connections with both the ventral striatum and medial OFC, and has been shown to be involved in reward and emotion processing in two other meta-analyses (Beckmann et al., 2009; Fujiwara et al., 2009).

\subsubsection{Modality-dependent activations in the lateral OFC}

Our results further revealed money-specific activations in the right anterior OFC. This finding supports the view that secondary (i.e. evolutionary recent) rewards such as money might recruit more anterior OFC regions than primary (i.e. evolutionary ancient) rewards such as food and sex (Kringelbach and Rolls, 2004; Sescousse et al., 2010). Such a dissociation is in line with the cytoarchitectonic properties of the OFC, showing that the anterior part, characterized by a granular cell layer, is phylogenetically more recent than the posterior part consisting in agranular and dysgranular cortices (Ongür and Price, 2000; Wise, 2008). A similar antero-posterior gradient has also been revealed using a functional parcellation of the OFC based on resting-state connectivity patterns with other brain regions (Kahnt et al., 2012). Furthermore, this hypothesis can be integrated in a broader perspective on frontal lobe organization, suggesting a trend in complexity and abstraction along a posterior-anterior axis with the frontopolar cortex at the apex (Badre and D'Esposito, 2009). For instance the rostro-caudal axis of the lateral prefrontal cortex (dIPFC) was shown to support a control hierarchy whereby posterior-to-anterior lateral PFC mediates progressively abstract, higherorder cognitive control (Dreher et al., 2008a; Koechlin et al., 2003). Along the same lines, patients with lesions in the anterior OFC have been reported to be specifically impaired in making decisions entailing abstract, i.e. distant, consequences, and not in making decisions leading to concrete, i.e. immediate, consequences, further supporting the idea of a posteroanterior trend in the representation of abstractness in the OFC (Bechara and Damasio, 2005). 
In accordance with the above hypothesis and previous results from our group (Sescousse et al., 2010), one would have expected primary rewards (i.e. food and erotic stimuli) to specifically recruit the posterior portion of the OFC in comparison to monetary rewards. Unfortunately we were not able to fully substantiate this claim, as the lateral posterior OFC was seemingly recruited by all three rewards in our meta-analysis (see Supplementary Materials - Fig. S1). Note however that erotic and food rewards did elicit activity in the lateral posterior OFC as expected. This is consistent with a recent report showing that aesthetic appraisal across diverse sensory modalities primarily recruits the OFC in its posterior part (Brown et al., 2011). Note also that the localization of reward-related activity in the lateral portion of the OFC challenges the hypothesis of a medio-lateral dissociation between rewards and punishments in the OFC (Noonan et al., 2012; O'Doherty, 2007)

\subsection{Amygdala}

\subsubsection{Modality-independent activations}

The amygdala receives projections from a number of cortical regions, but is most strongly connected to the ventral striatum and OFC (Haber and Knutson, 2010; Murray, 2007). Our meta-analysis showed that, in concert with these two regions, the amygdala responded to all rewards regardless of their type.

These results shed light on the debate opposing valence and salience coding in the amygdala. Early studies in humans and animals were mostly in favor of the valence hypothesis, suggesting that the amygdala is specialized in the processing of negative emotions such as fear or anger (LeDoux, 2000; Calder et al., 2001), or aversive stimuli such as unpleasant odors or monetary losses (Zald, 2003; Yacubian et al., 2006). Yet, the results from the present meta-analysis provide strong evidence that the amygdala is equally sensitive to rewarding stimuli, as confirmed by a wealth of animal studies (Sugase-Miyamoto and Richmond, 2005; Tye and Janak, 2007; Bermudez et al., 2012). This suggests that the amygdala might be better regarded as coding the salience, and not the valence, of affectively 
laden stimuli, consistent with the recent proposal of a salient prediction error computation in this region (Météreau and Dreher, 2012). Interestingly, several fMRI studies have manipulated both these dimensions while comparing positive and negative reinforcers of varying intensity in humans. In line with the salience hypothesis, they have shown that amygdala activity is linked to the level of arousal induced by these reinforcers, regardless of their valence (Small et al., 2003; Anderson and Sobel, 2003). Note however that the amygdala is a heterogeneous structure whose various nuclei are hardly distinguishable with fMRI, and that positive versus negative valence might still be encoded by distinct neuronal populations or distinct sub-regions (Prevost et al., 2011; Paton et al., 2006).

Despite the consistent response of the amygdala to rewarding stimuli, it is nevertheless unclear whether these responses reflect reward processing per se or assignment of emotional value. Based on seemingly overlapping brain mechanisms, emotion and reward have often been closely related and described together in a model where emotions are a by-product of reinforcement (Rolls, 2000). However, this view has been challenged by animal studies demonstrating that amygdala lesions may reduce emotional reactions without disturbing reward processing (Murray, 2007). As a consequence, it was proposed that, rather than a direct role in reward processing, the amygdala was in charge of providing an "affective tag" to stimuli. This is in line with several findings linking amygdala activity with skin conductance responses (SCR), thought to reflect autonomic responses (Bechara et al., 1999; Petrovic et al., 2008a). This emotional tagging would further participate in the updating of current reward value and the flexible adaptation of behavior, as illustrated by the decrease in amygdala activity following reinforcer devaluation (Baxter and Murray, 2002; Gottfried et al., 2003). Therefore, the activity observed in the amygdala in response to money, food and erotic pictures in the present meta-analysis is more likely to reflect the emotional impact of these stimuli rather than their intrinsic reward value.

\subsubsection{Modality-dependent activations}


Our meta-analysis also revealed that the amygdala, and possibly its centro-medial nucleus, was more reliably activated by erotic than by monetary and food rewards. This observation supports a role of the amygdala in the emotional appraisal of affectively laden reinforcers such as erotic pictures, known to elicit particularly strong affective and visceral reactions (Lang et al., 1993). In line with this interpretation, two recent studies showed enhanced amygdala activation in response to smiley faces and erotic pictures compared to monetary gains (Rademacher et al., 2010; Sescousse et al., 2010). The present result may also stem from the fact that, in contrast to monetary and food outcomes often delivered in a repetitive fashion in reward experiments, erotic stimuli are more salient and offer more variety, therefore limiting habituation effects commonly observed in the amygdala (Breiter et al., 1996). Moreover, one should note that most neuroimaging studies manipulating erotic rewards were conducted in men, who show significantly higher amygdala responses than women when presented with visual sexual stimuli (Hamann et al., 2004). Overall, our results are mostly compatible with an emotional account of amygdala function.

\subsection{Anterior insula}

\subsubsection{Modality-independent activations}

Our meta-analysis showed that the anterior insula bordering the frontal operculum was consistently activated by monetary, food and erotic rewards. Surprisingly, this structure has been relatively overlooked in the reward literature, and most often associated with aversive events such as monetary losses (Knutson and Bossaerts, 2007; Knutson and Greer, 2008; Petrovic et al., 2008b). We discuss below what might be its function in the processing of appetitive reward outcomes.

Whereas the posterior insula receives its main inputs from associative cortical regions, the anterior insula is mostly connected to limbic regions such as the vmPFC, amygdala and ventral striatum, and is essentially innervated by dopaminergic neurons. This situation enables the anterior insula to integrate autonomic and visceral information with emotional and motivational processes, in line with its proposed role in interoception (Naqvi 
and Bechara, 2009). Interoception consists in the neural mapping of bodily states which are meaningful for the maintenance of homeostasis, such as pain, thirst or autonomic arousal (Craig, 2002). These bodily states arise as a consequence of external emotional stimulation, but do not reach consciousness before they are mapped at the insular level. This mapping then leads to an explicit emotional feeling, after being integrated with the events originally eliciting those bodily states (Bechara and Damasio, 2005; Critchley, 2005). Importantly, the classic view of the anterior insula as a purely visceral sensory cortex was recently extended. Indeed, a number of neuroimaging studies have shown that it is involved in the representation of a wide variety of subjective feelings, and not just those arising from bodily states, as well as in many other cognitive processes such as attention, time perception or perceptual decision-making (Craig, 2009). Based on such evidence, the role of the anterior insula was reframed and associated more broadly with awareness. This generic account of anterior insula function is compatible with the bilateral activation observed across monetary, erotic and food outcomes, and suggests a role in the subjective affective experience of rewards. Moreover, the recruitment of the anterior insula by monetary rewards confirms that this region does not deal exclusively with bodily states relevant for homeostasis, but more generally with positive feelings elicited by pleasant outcomes.

Another function assigned to the anterior insula is the processing of risk and uncertainty (Knutson and Bossaerts, 2007; Craig, 2009; Singer et al., 2009). A wealth of fMRI studies using monetary (Huettel et al., 2006) and non-monetary stimuli (Huettel et al., 2005; Grinband et al., 2006) have demonstrated increased anterior insula activity when faced with risk or risky decisions. The consistency of this finding for risky monetary rewards was established in a recent meta-analysis, which further suggested that insular engagement might be even stronger when potential losses are involved (Mohr et al., 2010). Along the same lines, it has been proposed that the anterior insula computes a risk prediction and a "risk prediction error", and thus participates in risk learning (Preuschoff et al., 2008). This bears similarity to the concept of an "interoceptive prediction error", signaling mismatch between actual and anticipated bodily arousal, and suggested to play a role in anxiety 
(Paulus and Stein, 2006). It is further consistent with the idea that the anterior insula tracks the salience of outcomes, regardless of their valence (Rutledge et al., 2010) Thus, in the context of reward processing, the anterior insula might be in charge of tracking both expected and experienced risk, a mechanism that would participate more broadly in emotional appraisal.

\subsubsection{Modality-dependent activations}

Finally, although our results unambiguously support a role of the anterior insula in the processing of both primary and secondary rewards, they suggest a stronger involvement in the processing of primary rewards. Indeed, we found that the middle insula was more reliably activated by both erotic and food rewards as compared to money, while the ventral and dorsal parts of the anterior insula were more specifically recruited by erotic and food rewards, respectively. This is in agreement with a recent meta-analysis showing that aesthetic appraisal across various sensory modalities (i.e. primary rewards) produces very robust activations in the anterior insula (Brown et al., 2011). This could reflect the higher autonomic arousal induced by primary rewards: in line with their prominent role in homeostasis and survival, erotic and food rewards are known to generate acute changes in bodily states and autonomic arousal, as evidenced by changes in heart beat, skin conductance, sexual drive or satiety levels. Such changes are in turn often correlated with activity in the anterior insula, shown to be critically involved in autonomic conditioning (Critchley et al., 2002; Kuhn and Gallinat, 2011). The apparent segregation between erotic-specific and food-specific activations along a ventro-dorsal axis is difficult to interpret at this stage. Based on the role of the ventral insula in emotional appraisal and its frequent coactivation with the amygdala (Deen et al., 2010; Mutschler et al., 2009), the present result might reflect the particularly strong emotional impact of erotic rewards. The activation observed in the anterior insula for food rewards is consistent with the location of the primary gustatory cortex (Naqvi and 
Bechara, 2009). This is further consistent with the food-specific activation observed in the somatosensory cortex and adjacent middle insula, known to be involved in the processing of the physical properties of food and the mapping of bodily states (Bechara and Damasio, 2005). Therefore, it is possible that those food-specific activations reflect the sensory properties of food rewards, rather than their specificity as a primary reward.

\subsection{Mediodorsal thalamus}

Our meta-analysis revealed that the mediodorsal thalamus, a structure which is rarely discussed in the reward literature, was consistently activated by monetary, erotic and food rewards. This brain region is an important relay between the basal ganglia and the prefrontal cortex: it receives inputs from the ventral striatum via the ventral pallidum, and projects in turn to various regions of the prefrontal cortex, especially the ventromedial part, which projects back to the ventral striatum (Haber and Knutson, 2010; Ongür and Price, 2000; Garcia-Cabezas et al., 2007). Embedded within this striatal-thalamo-cortical loop, the mediodorsal thalamus is thought to bridge basic reward signals with higher cognitive processes such as motivation and goal-directed behaviour (Elliott et al., 2000; Galvan et al., 2005).

The role of the mediodorsal thalamus in reward prediction is supported by a wealth of studies in both animals and humans. In rats, thalamic neurons were found to fire in anticipation of pleasant food rewards (Komura et al., 2001), while lesions in the mediodorsal thalamus were found to impair instrumental conditioning (Corbit et al., 2003). In humans, reward predictive cues were found to elicit robust thalamic activity, often increasing with reward probability (Galvan et al., 2005; Roiser et al., 2010). A meta-analysis further revealed that this activity was stronger than the one observed at the time of reward outcome (Knutson 
and Greer, 2008). These anticipatory responses have generally been interpreted as reflecting increased attention towards motivationally salient stimuli.

Importantly, the present results demonstrate that the mediodorsal thalamus also plays an important role in processing the experienced value of rewards. Interestingly, activity in the thalamus was found to scale with reward intensity in a number of studies manipulating monetary gains (Martin-Soelch et al., 2003; Elliott et al., 2000), erotic stimuli (Redouté et al., 2000) or pleasant music (Blood and Zatorre, 2001). These results can be interpreted within the previous framework, i.e. as reflecting increased arousal, but could alternatively be seen as reflecting reward value coding. However, if the mediodorsal thalamus reflected reward value, we should expect positive reinforcement to produce much higher thalamic activity than negative reinforcement. This does not seem to be the case in our meta-analysis: out of the nine monetary studies using contrasts between gains and losses, only one reported activity in the thalamus (Cox et al., 2005). This is consistent with a meta-analysis showing that anticipation of reward versus punishment does not elicit differential activation in the thalamus (Knutson and Greer, 2008). Hence, although more research is needed to confirm this hypothesis, it is possible that the currently observed mediodorsal thalamus activity reflects the general arousal induced by behaviorally salient rewards. This is in line with a recent study in which monetary rewards, found to be motivationally more salient than social rewards (as objectivised by faster reaction times), also elicited higher thalamic activation (Rademacher et al., 2010). It is also consistent with a study investigating sexual orientation, and showing that despite similar attractiveness judgments, faces of the preferred sex elicited higher activity in the mediodorsal thalamus than less salient faces of the non-preferred sex (Kranz and Ishai, 2006).

\subsection{The hypothalamus and extrastriate body area}


Finally, our meta-analysis revealed that the hypothalamus and extrastriate body area, two brain regions not usually associated with reward processing, were robustly and specifically activated by erotic rewards.

The hypothalamus is part of the limbic system and plays a general role in homeostatic control and autonomic responses, essentially by means of its neuroendocrine function. In particular, it is known to be important for feeding behaviour, and its activity was shown to be modulated by food cues as well as by hunger and satiety feelings (Grabenhorst et al., 2010b; Hikosaka et al., 2008). However, this role seems to be distinct from the coding of food hedonics, as illustrated by the absence of hypothalamic response to pleasant foods in our meta-analysis. In contrast, the hypothalamus appeared to be particularly sensitive to the presentation of visual erotic stimuli, consistent with the rich animal and human literature demonstrating the pivotal role of this region in sexual behaviour (Karama et al., 2002; Walter et al., 2008). Several neuroimaging studies have found a correlation of hypothalamic activity with subjective sexual arousal, as well as with physiological arousal responses in men, such as erection (Arnow et al., 2002; Karama et al., 2002; Redouté et al., 2000). Overall these results confirm the central role of the hypothalamus in human sexual motivation, although this role might be more likely related to the regulation of autonomic responses than to the appraisal process through which erotic stimuli are evaluated as sexual incentives (Redouté et al., 2000).

Erotic stimuli also elicited large activations in the extrastriate body area, a higher order visual area of the lateral occipitotemporal cortex, known to selectively respond to images of the human body or parts of it (Downing et al., 2001). This result is consistent with the nature of erotic stimuli typically representing naked bodies. Moreover, several studies found that these activations appeared to be independent of the gender of the bodies displayed and the individuals' sexual preference (Paul et al., 2008; Ponseti et al., 2006). This suggests that the extrastriate body area is mainly sensitive to the visual features of erotic stimuli, rather than to their rewarding properties. 


\subsection{Limitations and strengths}

The present meta-analysis is not free of limitations, demanding to treat the results with some caution. First, our ALE approach ignored information such as peak statistical values or spatial extent of functional clusters reported in individual studies. Yet, it would be desirable to weigh included studies depending on these criteria, as they often reflect the underlying quality of the imaging results (Yarkoni et al., 2010). Note however, that this ideal procedure is difficult to implement and seldom used in practice, because of the need to possess full datasets processed in a homogeneous fashion.

An additional limitation might come from the heterogeneity of the tasks used in the reward literature and included in our meta-analysis. First, variations in reward delivery may act as a confounding effect. As mentioned previously, monetary studies often involve probabilistic or performance-dependent rewards, whereas food and erotic rewards are usually delivered in a passive and predictable way. Moreover, a number of food and erotic studies used block designs, whereas most monetary studies used event-related designs. These methodological discrepancies may confound effects related to reward type with effects related to how rewards are delivered. Note however that the difference in block versus eventrelated designs does not seem to impact reward-related activations, at least for erotic stimuli (Buhler et al., 2008). Furthermore, within each reward category, we combined foci resulting from a wide variety of protocols and contrasts. As a consequence, we might have pooled rather heterogeneous results: for instance, a contrast between gains and losses in a guessing task is likely to produce different activations from a contrast between gains and non-gains in a classical conditioning task. This has the advantage of revealing the most robust and replicable effects across paradigms, but the disadvantage of limiting our ability to ascribe specific brain regions to discrete reward processes.

Finally, it could be argued that the differential activation patterns presently observed between rewards are confounded by differences in reward intensity. Disentangling these two hypotheses is intrinsically difficult within a meta-analysis. Indeed, in contrast to single studies in which the matching of different conditions is under the control of the experimenter, such 
matching cannot be easily achieved when comparing different groups of studies. However, it should be noted that since this is a coordinate-based meta-analysis, we are not comparing the amplitude of brain activity between conditions (as would be done by contrasting Betas within a regular GLM analysis), but the spatial consistency of reported peaks of activity between groups of studies (regardless of peak t-values). Yet, this consistency is not influenced by the intensity of the reward stimuli, but rather by their ability to elicit reliable and detectable activity in the brain.

Finally, one might be surprised not to observe midbrain activity emerging from our meta-analysis. In fact, all three rewards did elicit activity in the midbrain, but the location of functional clusters was not overlapping between rewards and was not entirely consistent with the dopaminergic portion of the midbrain (see Supplementary Materials - Fig. S2). This variability likely results from the high susceptibility of fMRI signals in the midbrain to noise and artifacts, due to local field inhomogeneity, motion and partial volume effects (Haber and Knutson, 2010; D'Ardenne et al., 2008). This loss of reliability of fMRI signals in deeper brain structures warrants a word of caution in interpreting the present results as a truly whole-brain picture of reward-related activity, and calls in turn for adapted data acquisition protocols for those regions in the future (Krebs et al., 2011; D'Ardenne et al., 2008).

Despite these limitations, the present work has several important strengths. To the best of our knowledge, this is the first study to systematically compare the neuroanatomical substrates of multiple rewards in order to distinguish common from specialized rewardrelated regions. Moreover, these comparisons were performed in a fully objective manner, since we used a voxel-based meta-analytic approach combined with whole-brain results only. In particular, by excluding ROI-based studies from our meta-analysis, we avoided the confirmation bias inherent to the ROI approach, and were able to reveal the most consistent findings in the absence of any a priori assumptions. In fact, we had to exclude a surprisingly high number of ROI-based studies, which is somehow paradoxical considering the only recent availability of objective reference (such as the present meta-analysis) for these studies in the literature. Perhaps as a consequence, our findings showed that regions such 
as the thalamus and anterior insula were more robustly activated by reward outcomes than previously thought. Finally, we used a quantitative, random-effect, approach based on the estimated convergence of results across studies. This provides valuable information in terms of average peak location and spatial extent of reward-related brain regions, which should prove useful for future ROI-based studies.

\subsection{Conclusions}

This meta-analysis first reveals that there is ample support in the neuroimaging literature for a "common reward circuit" in the brain (Fig. 3). Although this finding was to be expected, our results offer an objective and quantitative demonstration. Within this circuit, the vmPFC appears to be directly responsible for computing the experienced value of rewards on a common scale. Strongly connected to the vmPFC, the ventral striatum is thought to primarily reflect prediction error and to contribute to learning and motivation, although its pattern of activation is also compatible with the computation of experienced value. Interestingly, both the vmPFC and ventral striatum have been involved in the valuation phase of a number of decision-making paradigms involving primary and secondary rewards (Kable et al., 2007; Prévost et al., 2010). Further meta-analyses are needed to investigate whether the computation of experienced value and decision value also engages distinct brain structures. As for the amygdala, even though its involvement in reward learning is still a matter of debate, considerable evidence shows that it plays a major role in assigning emotional value to rewards. Less often included in the canonical definition of the reward circuit, the anterior insula emerged as a key region in our meta-analysis. Its role in reward processing is likely related to the conscious awareness of emotions triggered by rewards, or to risk and salience monitoring. The mediodorsal thalamus, strongly activated by all rewards, is thought to play a role in the increased arousal induced by rewards. Importantly, in all these regions except the thalamus, our analyses revealed variations in peaks or levels of activity depending on reward type. These discrepancies are presumably attributable to intrinsic 
differences between rewards or between the contexts in which these rewards were delivered. Note that these discrepancies might be informative and help elucidate the functional roles of specific brain regions in reward processing. For instance, the stronger activation observed in the ventral striatum for monetary rewards can be related to the frequent delivery of these rewards in a learning context, and therefore tends to support a role for this brain region in prediction error computation.

Complementing this common reward circuit, our meta-analysis revealed specialized reward areas in the brain. The recruitment of specific regions, including the somatosensory cortex (food-specific), extrastriate body area and hypothalamus (erotic-specific), is likely driven by sensory or autonomic properties of the rewards under scrutiny. In addition, the anterior OFC was specifically recruited by monetary rewards, a result that we interpret in the broader perspective of a dissociation between primary and secondary rewards in the postero-anterior axis of the OFC (Sescousse et al., 2010).

The question of one versus multiple reward circuits in the brain is complex and requires future development. First, it will be instructive to extend the present work in the future, when enough data has been accumulated to run meta-analyses on other types of rewards, such as beautiful faces, pleasant odors or positive social feedback. Addressing previously stated methodological limitations will be another challenge. Image-based metaanalyses, which make use of crucial information such as activation magnitude and spatial extent of clusters, but require access to the original data, seem like a promising avenue (Salimi-Khorshidi et al., 2009; Poldrack, 2008). The present meta-analysis was focused on the identification of reward-related regions, and studied how the engagement of these regions varies with reward type. Alternatively, it would be informative to investigate how the engagement of these regions varies with task characteristics. As previously mentioned, brain response patterns are likely to fluctuate with the mode of reward delivery, depending on the requirement of a motor response (e.g. passive versus active reward), the involvement of learning (e.g. strategic versus guessing reward task), or the degree of expectation (e.g. probabilistic versus certain rewards). Comparative meta-analyses of reward studies based 
on these criteria would provide valuable insight into the functional roles of reward-related regions, and help in turn to build a cognitive ontology of reward processing (Poldrack, 2008; Yarkoni et al., 2010).

\section{References}

Abler, B., Erk, S., Walter, H., 2007. Human reward system activation is modulated by a single dose of olanzapine in healthy subjects in an event-related, double-blind, placebocontrolled fMRI study. Psychopharmacology (Berl) 191, 823-833.

Aharon, I., Etcoff, N., Ariely, D., Chabris, C.F., O'Connor, E., Breiter, H.C., 2001. Beautiful faces have variable reward value: fMRI and behavioral evidence. Neuron 32, 537-551.

Anderson, A.K., Sobel, N., 2003. Dissociating intensity from valence as sensory inputs to emotion. Neuron 39, 581-583.

Arnow, B.A., Desmond, J.E., Banner, L.L., Glover, G.H., Solomon, A., Polan, M.L., Lue, T.F., Atlas, S.W., 2002. Brain activation and sexual arousal in healthy, heterosexual males. Brain 125, 1014-1023.

Asensio, S., Romero, M.J., Palau, C., Sanchez, A., Senabre, I., Morales, J.L., Carcelen, R., Romero, F.J., 2010. Altered neural response of the appetitive emotional system in cocaine addiction: an fMRI Study. Addict Biol 15, 504-516.

Badre, D., D'Esposito, M., 2009. Is the rostro-caudal axis of the frontal lobe hierarchical? Nat Rev Neurosci 10, 659-669.

Barros-Loscertales, A., Ventura-Campos, N., Sanjuan-Tomas, A., Belloch, V., Parcet, M.A., Avila, C., 2010. Behavioral activation system modulation on brain activation during appetitive and aversive stimulus processing. Soc Cogn Affect Neurosci 5, 18-28.

Baxter, M.G., Murray, E.A., 2002. The amygdala and reward. Nat Rev Neurosci 3, 563-573.

Beauregard, M., Levesque, J., Bourgouin, P., 2001. Neural correlates of conscious selfregulation of emotion. J Neurosci 21, RC165.

Bechara, A., Damasio, A., 2005. The somatic marker hypothesis: A neural theory of economic decision. Games and Economic Behavior 52, 336-372.

Bechara, A., Damasio, H., Damasio, A.R., Lee, G.P., 1999. Different contributions of the human amygdala and ventromedial prefrontal cortex to decision-making. J Neurosci 19, 5473-5481.

Beckmann, M., Johansen-Berg, H., Rushworth, M.F., 2009. Connectivity-based parcellation of human cingulate cortex and its relation to functional specialization. J Neurosci 29, 1175-1190.

Bermudez, M.A., Gobel, C., Schultz, W., 2012. Sensitivity to Temporal Reward Structure in Amygdala Neurons. Curr Biol.

Berns, G.S., McClure, S.M., Pagnoni, G., Montague, P.R., 2001. Predictability modulates human brain response to reward. J Neurosci 21, 2793-2798.

Berridge, K.C., 2003. Pleasures of the brain. Brain Cogn 52, 106-128.

Berridge, K.C., 2007. The debate over dopamine's role in reward: the case for incentive salience. Psychopharmacology (Berl) 191, 391-431.

Berridge, K.C., Robinson, T.E., 2003. Parsing reward. Trends Neurosci 26, 507-513. 
Bjork, J.M., Knutson, B., Fong, G.W., Caggiano, D.M., Bennett, S.M., Hommer, D.W., 2004. Incentive-elicited brain activation in adolescents: similarities and differences from young adults. J Neurosci 24, 1793-1802.

Bjork, J.M., Smith, A.R., Chen, G., Hommer, D.W., 2010. Adolescents, adults and rewards: comparing motivational neurocircuitry recruitment using fMRI. PLoS One 5, e11440.

Bjork, J.M., Smith, A.R., Hommer, D.W., 2008. Striatal sensitivity to reward deliveries and omissions in substance dependent patients. Neuroimage 42, 1609-1621.

Blood, A.J., Zatorre, R.J., 2001. Intensely pleasurable responses to music correlate with activity in brain regions implicated in reward and emotion. Proc Natl Acad Sci U S A 98, 11818-11823.

Bocher, M., Chisin, R., Parag, Y., Freedman, N., Meir Weil, Y., Lester, H., Mishani, E., Bonne, O., 2001. Cerebral activation associated with sexual arousal in response to a pornographic clip: A 15O-H2O PET study in heterosexual men. Neuroimage 14, 105117.

Bray, S., O'Doherty, J., 2007. Neural coding of reward-prediction error signals during classical conditioning with attractive faces. J Neurophysiol 97, 3036-3045.

Breiter, H.C., Etcoff, N.L., Whalen, P.J., Kennedy, W.A., Rauch, S.L., Buckner, R.L., Strauss, M.M., Hyman, S.E., Rosen, B.R., 1996. Response and habituation of the human amygdala during visual processing of facial expression. Neuron 17, 875-887.

Brown, S., Gao, X., Tisdelle, L., Eickhoff, S.B., Liotti, M., 2011. Naturalizing aesthetics: brain areas for aesthetic appraisal across sensory modalities. Neuroimage 58, 250-258.

Brunetti, M., Babiloni, C., Ferretti, A., Del Gratta, C., Merla, A., Olivetti Belardinelli, M., Romani, G.L., 2008. Hypothalamus, sexual arousal and psychosexual identity in human males: a functional magnetic resonance imaging study. Eur J Neurosci 27, 2922-2927.

Buhler, M., Vollstadt-Klein, S., Klemen, J., Smolka, M.N., 2008. Does erotic stimulus presentation design affect brain activation patterns? Event-related vs. blocked fMRI designs. Behav Brain Funct 4, 30.

Calder, A.J., Lawrence, A.D., Young, A.W., 2001. Neuropsychology of fear and loathing. Nat Rev Neurosci 2, 352-363.

Camara, E., Rodriguez-Fornells, A., Munte, T.F., 2008. Functional connectivity of reward processing in the brain. Front Hum Neurosci 2, 19.

Cauda, F., Cavanna, A.E., D'Agata, F., Sacco, K., Duca, S., Geminiani, G.C., 2011. Functional connectivity and coactivation of the nucleus accumbens: a combined functional connectivity and structure-based meta-analysis. J Cogn Neurosci 23, 28642877.

Chib, V.S., Rangel, A., Shimojo, S., O'Doherty, J.P., 2009. Evidence for a common representation of decision values for dissimilar goods in human ventromedial prefrontal cortex. J Neurosci 29, 12315-12320.

Clark, L., Lawrence, A.J., Astley-Jones, F., Gray, N., 2009. Gambling near-misses enhance motivation to gamble and recruit win-related brain circuitry. Neuron 61, 481-490.

Corbit, L.H., Muir, J.L., Balleine, B.W., 2003. Lesions of mediodorsal thalamus and anterior thalamic nuclei produce dissociable effects on instrumental conditioning in rats. Eur $\mathrm{J}$ Neurosci 18, 1286-1294.

Cox, S.M., Andrade, A., Johnsrude, I.S., 2005. Learning to like: a role for human orbitofrontal cortex in conditioned reward. J Neurosci 25, 2733-2740.

Craig, A.D., 2002. How do you feel? Interoception: the sense of the physiological condition of the body. Nat Rev Neurosci 3, 655-666.

Craig, A.D., 2009. How do you feel--now? The anterior insula and human awareness. Nat Rev Neurosci 10, 59-70. 
Critchley, H.D., 2005. Neural mechanisms of autonomic, affective, and cognitive integration. J Comp Neurol 493, 154-166.

Critchley, H.D., Mathias, C.J., Dolan, R.J., 2002. Fear conditioning in humans: the influence of awareness and autonomic arousal on functional neuroanatomy. Neuron 33, 653663.

D'Ardenne, K., McClure, S.M., Nystrom, L.E., Cohen, J.D., 2008. BOLD responses reflecting dopaminergic signals in the human ventral tegmental area. Science 319, 1264-1267.

de Araujo, I.E., Rolls, E.T., Kringelbach, M.L., McGlone, F., Phillips, N., 2003. Tasteolfactory convergence, and the representation of the pleasantness of flavour, in the human brain. Eur J Neurosci 18, 2059-2068.

Deen, B., Pitskel, N.B., Pelphrey, K.A., 2010. Three Systems of Insular Functional Connectivity Identified with Cluster Analysis. Cereb Cortex epub.

Del Parigi, A., Chen, K., Salbe, A.D., Gautier, J.F., Ravussin, E., Reiman, E.M., Tataranni, P.A., 2002. Tasting a liquid meal after a prolonged fast is associated with preferential activation of the left hemisphere. Neuroreport 13, 1141-1145.

Delgado, M.R., 2007. Reward-related responses in the human striatum. Ann N Y Acad Sci 1104, 70-88.

Delgado, M.R., Li, J., Schiller, D., Phelps, E.A., 2008. The role of the striatum in aversive learning and aversive prediction errors. Philos Trans R Soc Lond B Biol Sci 363, 3787-3800.

Domenech, P., Dreher, J.C., 2008. Distinguishing two brain systems involved in choosing between different types of rewards. Society for Neuroscience Annual Meeting, Washington DC.

Downing, P.E., Jiang, Y., Shuman, M., Kanwisher, N., 2001. A cortical area selective for visual processing of the human body. Science 293, 2470-2473.

Dreher, J.C., Koechlin, E., Tierney, M., Grafman, J., 2008a. Damage to the fronto-polar cortex is associated with impaired multitasking. PLoS One 3, e3227.

Dreher, J.C., Meyer-Lindenberg, A., Kohn, P., Berman, K.F., 2008b. Age-related changes in midbrain dopaminergic regulation of the human reward system. Proc Natl Acad Sci U S A 105, 15106-15111.

Eickhoff, S.B., Bzdok, D., Laird, A.R., Kurth, F., Fox, P.T., 2012. Activation likelihood estimation meta-analysis revisited. Neuroimage 59, 2349-2361.

Eickhoff, S.B., Laird, A.R., Grefkes, C., Wang, L.E., Zilles, K., Fox, P.T., 2009. Coordinatebased activation likelihood estimation meta-analysis of neuroimaging data: a randomeffects approach based on empirical estimates of spatial uncertainty. Hum Brain Mapp 30, 2907-2926.

Elliott, R., Friston, K.J., Dolan, R.J., 2000. Dissociable neural responses in human reward systems. J Neurosci 20, 6159-6165.

Elliott, R., Newman, J.L., Longe, O.A., Deakin, J.F., 2003. Differential response patterns in the striatum and orbitofrontal cortex to financial reward in humans: a parametric functional magnetic resonance imaging study. J Neurosci 23, 303-307.

Elliott, R., Newman, J.L., Longe, O.A., William Deakin, J.F., 2004. Instrumental responding for rewards is associated with enhanced neuronal response in subcortical reward systems. Neuroimage 21, 984-990.

Erk, S., Spitzer, M., Wunderlich, A.P., Galley, L., Walter, H., 2002. Cultural objects modulate reward circuitry. Neuroreport 13, 2499-2503.

Ernst, M., Nelson, E.E., Jazbec, S., McClure, E.B., Monk, C.S., Leibenluft, E., Blair, J., Pine, D.S., 2005. Amygdala and nucleus accumbens in responses to receipt and omission of gains in adults and adolescents. Neuroimage 25, 1279-1291. 
Felsted, J.A., Ren, X., Chouinard-Decorte, F., Small, D.M., 2010. Genetically determined differences in brain response to a primary food reward. J Neurosci 30, 2428-2432.

Ferretti, A., Caulo, M., Del Gratta, C., Di Matteo, R., Merla, A., Montorsi, F., Pizzella, V., Pompa, P., Rigatti, P., Rossini, P.M., Salonia, A., Tartaro, A., Romani, G.L., 2005. Dynamics of male sexual arousal: distinct components of brain activation revealed by fMRI. Neuroimage 26, 1086-1096.

FitzGerald, T.H., Seymour, B., Dolan, R.J., 2009. The role of human orbitofrontal cortex in value comparison for incommensurable objects. J Neurosci 29, 8388-8395.

Francis, S., Rolls, E.T., Bowtell, R., McGlone, F., O'Doherty, J., Browning, A., Clare, S., Smith, E., 1999. The representation of pleasant touch in the brain and its relationship with taste and olfactory areas. Neuroreport 10, 453-459.

Fujiwara, J., Tobler, P.N., Taira, M., Iijima, T., Tsutsui, K., 2009. Segregated and integrated coding of reward and punishment in the cingulate cortex. J Neurophysiol 101, 32843293.

Galvan, A., Hare, T.A., Davidson, M., Spicer, J., Glover, G., Casey, B.J., 2005. The role of ventral frontostriatal circuitry in reward-based learning in humans. J Neurosci 25, 8650-8656.

Garcia-Cabezas, M.A., Rico, B., Sanchez-Gonzalez, M.A., Cavada, C., 2007. Distribution of the dopamine innervation in the macaque and human thalamus. Neuroimage 34, 965984.

Gottfried, J.A., O'Doherty, J., Dolan, R.J., 2003. Encoding predictive reward value in human amygdala and orbitofrontal cortex. Science 301, 1104-1107.

Grabenhorst, F., D'Souza, A.A., Parris, B.A., Rolls, E.T., Passingham, R.E., 2010a. A common neural scale for the subjective pleasantness of different primary rewards. Neuroimage 51, 1265-1274.

Grabenhorst, F., Rolls, E.T., Parris, B.A., d'Souza, A.A., 2010b. How the brain represents the reward value of fat in the mouth. Cereb Cortex 20, 1082-1091.

Green, E., Murphy, C., 2012. Altered processing of sweet taste in the brain of diet soda drinkers. Physiol Behav.

Grinband, J., Hirsch, J., Ferrera, V.P., 2006. A neural representation of categorization uncertainty in the human brain. Neuron 49, 757-763.

Haase, L., Cerf-Ducastel, B., Murphy, C., 2009. Cortical activation in response to pure taste stimuli during the physiological states of hunger and satiety. Neuroimage 44, 10081021.

Haber, S.N., Knutson, B., 2010. The reward circuit: linking primate anatomy and human imaging. Neuropsychopharmacology 35, 4-26.

Hamann, S., Herman, R.A., Nolan, C.L., Wallen, K., 2004. Men and women differ in amygdala response to visual sexual stimuli. Nat Neurosci 7, 411-416.

Hammers, A., Allom, R., Koepp, M.J., Free, S.L., Myers, R., Lemieux, L., Mitchell, T.N., Brooks, D.J., Duncan, J.S., 2003. Three-dimensional maximum probability atlas of the human brain, with particular reference to the temporal lobe. Hum Brain Mapp 19, 224247.

Hardin, M.G., Pine, D.S., Ernst, M., 2009. The influence of context valence in the neural coding of monetary outcomes. Neuroimage 48, 249-257.

Hare, T.A., Camerer, C.F., Rangel, A., 2009. Self-control in decision-making involves modulation of the vmPFC valuation system. Science 324, 646-648.

Hare, T.A., O'Doherty, J., Camerer, C.F., Schultz, W., Rangel, A., 2008. Dissociating the role of the orbitofrontal cortex and the striatum in the computation of goal values and prediction errors. J Neurosci 28, 5623-5630. 
Hikosaka, O., Bromberg-Martin, E., Hong, S., Matsumoto, M., 2008. New insights on the subcortical representation of reward. Curr Opin Neurobiol 18, 203-208.

Hu, S.H., Wei, N., Wang, Q.D., Yan, L.Q., Wei, E.Q., Zhang, M.M., Hu, J.B., Huang, M.L., Zhou, W.H., Xu, Y., 2008. Patterns of brain activation during visually evoked sexual arousal differ between homosexual and heterosexual men. AJNR Am J Neuroradiol 29, 1890-1896.

Huettel, S.A., Song, A.W., McCarthy, G., 2005. Decisions under uncertainty: probabilistic context influences activation of prefrontal and parietal cortices. J Neurosci 25, 33043311.

Huettel, S.A., Stowe, C.J., Gordon, E.M., Warner, B.T., Platt, M.L., 2006. Neural signatures of economic preferences for risk and ambiguity. Neuron 49, 765-775.

Izuma, K., Saito, D.N., Sadato, N., 2008. Processing of social and monetary rewards in the human striatum. Neuron 58, 284-294.

Jacobson, A., Green, E., Murphy, C., 2010. Age-related functional changes in gustatory and reward processing regions: An fMRI study. Neuroimage 53, 602-610.

Kahnt, T., Chang, L.J., Park, S.Q., Heinzle, J., Haynes, J.D., 2012. Connectivity-based parcellation of the human orbitofrontal cortex. J Neurosci 32, 6240-6250.

Kampe, K.K., Frith, C.D., Dolan, R.J., Frith, U., 2001. Reward value of attractiveness and gaze. Nature 413, 589.

Karama, S., Lecours, A.R., Leroux, J.M., Bourgouin, P., Beaudoin, G., Joubert, S., Beauregard, M., 2002. Areas of brain activation in males and females during viewing of erotic film excerpts. Hum Brain Mapp 16, 1-13.

Kim, S.W., Sohn, D.W., Cho, Y.H., Yang, W.S., Lee, K.U., Juh, R., Ahn, K.J., Chung, Y.A., Han, S.I., Lee, K.H., Lee, C.U., Chae, J.H., 2006. Brain activation by visual erotic stimuli in healthy middle aged males. Int J Impot Res 18, 452-457.

Knutson, B., Bhanji, J.P., Cooney, R.E., Atlas, L.Y., Gotlib, I.H., 2008. Neural responses to monetary incentives in major depression. Biol Psychiatry 63, 686-692.

Knutson, B., Bossaerts, P., 2007. Neural antecedents of financial decisions. J Neurosci 27, 8174-8177.

Knutson, B., Fong, G.W., Adams, C.M., Varner, J.L., Hommer, D., 2001. Dissociation of reward anticipation and outcome with event-related fMRI. Neuroreport 12, 36833687.

Knutson, B., Fong, G.W., Bennett, S.M., Adams, C.M., Hommer, D., 2003. A region of mesial prefrontal cortex tracks monetarily rewarding outcomes: characterization with rapid event-related fMRI. Neuroimage 18, 263-272.

Knutson, B., Greer, S.M., 2008. Anticipatory affect: neural correlates and consequences for choice. Philos Trans R Soc Lond B Biol Sci 363, 3771-3786.

Knutson, B., Rick, S., Wimmer, G.E., Prelec, D., Loewenstein, G., 2007. Neural predictors of purchases. Neuron 53, 147-156.

Koechlin, E., Ody, C., Kouneiher, F., 2003. The architecture of cognitive control in the human prefrontal cortex. Science 302, 1181-1185.

Komura, Y., Tamura, R., Uwano, T., Nishijo, H., Kaga, K., Ono, T., 2001. Retrospective and prospective coding for predicted reward in the sensory thalamus. Nature 412, 546-549.

Kranz, F., Ishai, A., 2006. Face perception is modulated by sexual preference. Curr Biol 16, 63-68.

Krebs, R.M., Heipertz, D., Schuetze, H., Duzel, E., 2011. Novelty increases the mesolimbic functional connectivity of the substantia nigra/ventral tegmental area (SN/VTA) during reward anticipation: Evidence from high-resolution fMRI. Neuroimage 58, 647-655. 
Kringelbach, M.L., O'Doherty, J., Rolls, E.T., Andrews, C., 2003. Activation of the human orbitofrontal cortex to a liquid food stimulus is correlated with its subjective pleasantness. Cereb Cortex 13, 1064-1071.

Kringelbach, M.L., Rolls, E.T., 2004. The functional neuroanatomy of the human orbitofrontal cortex: evidence from neuroimaging and neuropsychology. Prog Neurobiol 72, 341-372.

Kuhn, S., Gallinat, J., 2011. A quantitative meta-analysis on cue-induced male sexual arousal. J Sex Med 8, 2269-2275.

Kuhn, S., Gallinat, J., 2012. The neural correlates of subjective pleasantness. Neuroimage 61, 289-294.

Kunig, G., Leenders, K.L., Martin-Solch, C., Missimer, J., Magyar, S., Schultz, W., 2000. Reduced reward processing in the brains of Parkinsonian patients. Neuroreport 11, 3681-3687.

Laird, A.R., Fox, P.M., Price, C.J., Glahn, D.C., Uecker, A.M., Lancaster, J.L., Turkeltaub, P.E., Kochunov, P., Fox, P.T., 2005. ALE meta-analysis: controlling the false discovery rate and performing statistical contrasts. Hum Brain Mapp 25, 155-164.

Lancaster, J.L., Woldorff, M.G., Parsons, L.M., Liotti, M., Freitas, C.S., Rainey, L., Kochunov, P.V., Nickerson, D., Mikiten, S.A., Fox, P.T., 2000. Automated Talairach atlas labels for functional brain mapping. Hum Brain Mapp 10, 120-131.

Lang, P.J., Greenwald, M.K., Bradley, M.M., Hamm, A.O., 1993. Looking at pictures: affective, facial, visceral, and behavioral reactions. Psychophysiology 30, 261-273.

LeDoux, J.E., 2000. Emotion circuits in the brain. Annu Rev Neurosci 23, 155-184.

Linke, J., Kirsch, P., King, A.V., Gass, A., Hennerici, M.G., Bongers, A., Wessa, M., 2010. Motivational orientation modulates the neural response to reward. Neuroimage 49, 2618-2625.

Liu, X., Hairston, J., Schrier, M., Fan, J., 2011. Common and distinct networks underlying reward valence and processing stages: a meta-analysis of functional neuroimaging studies. Neurosci Biobehav Rev 35, 1219-1236.

Martin-Soelch, C., Missimer, J., Leenders, K.L., Schultz, W., 2003. Neural activity related to the processing of increasing monetary reward in smokers and nonsmokers. Eur $\mathrm{J}$ Neurosci 18, 680-688.

Martin-Solch, C., Magyar, S., Kunig, G., Missimer, J., Schultz, W., Leenders, K.L., 2001. Changes in brain activation associated with reward processing in smokers and nonsmokers. A positron emission tomography study. Exp Brain Res 139, 278-286.

Martin, L.E., Potts, G.F., Burton, P.C., Montague, P.R., 2009. Electrophysiological and hemodynamic responses to reward prediction violation. Neuroreport 20, 1140-1143.

McCabe, C., Huber, A., Harmer, C.J., Cowen, P.J., 2011. The D2 antagonist sulpiride modulates the neural processing of both rewarding and aversive stimuli in healthy volunteers. Psychopharmacology (Berl) 217, 271-278.

McCabe, C., Rolls, E.T., 2007. Umami: a delicious flavor formed by convergence of taste and olfactory pathways in the human brain. The European journal of neuroscience 25, 1855-1864.

McClure, S.M., Berns, G.S., Montague, P.R., 2003. Temporal prediction errors in a passive learning task activate human striatum. Neuron 38, 339-346.

McClure, S.M., Li, J., Tomlin, D., Cypert, K.S., Montague, L.M., Montague, P.R., 2004a. Neural correlates of behavioral preference for culturally familiar drinks. Neuron 44, 379-387.

McClure, S.M., York, M.K., Montague, P.R., 2004b. The neural substrates of reward processing in humans: the modern role of FMRI. Neuroscientist 10, 260-268. 
Menon, V., Levitin, D.J., 2005. The rewards of music listening: response and physiological connectivity of the mesolimbic system. Neuroimage 28, 175-184.

Météreau, E., Dreher, J.C., 2012. Cerebral correlates of salient prediction error for different rewards and punishments. Cereb Cortex. doi:10.1093/cercor/bhs037.

Mohr, P.N., Biele, G., Heekeren, H.R., 2010. Neural processing of risk. J Neurosci 30, 66136619.

Moulier, V., Mouras, H., Pelegrini-Issac, M., Glutron, D., Rouxel, R., Grandjean, B., Bittoun, J., Stoleru, S., 2006. Neuroanatomical correlates of penile erection evoked by photographic stimuli in human males. Neuroimage 33, 689-699.

Mouras, H., Stoleru, S., Moulier, V., Pelegrini-Issac, M., Rouxel, R., Grandjean, B., Glutron, D., Bittoun, J., 2008. Activation of mirror-neuron system by erotic video clips predicts degree of induced erection: an fMRI study. Neuroimage 42, 1142-1150.

Murray, E.A., 2007. The amygdala, reward and emotion. Trends Cogn Sci 11, 489-497.

Mutschler, I., Wieckhorst, B., Kowalevski, S., Derix, J., Wentlandt, J., Schulze-Bonhage, A., Ball, T., 2009. Functional organization of the human anterior insular cortex. Neuroscience letters 457, 66-70.

Naqvi, N.H., Bechara, A., 2009. The hidden island of addiction: the insula. Trends Neurosci 32, 56-67.

Nestler, E.J., 2005. Is there a common molecular pathway for addiction? Nat Neurosci 8, 1445-1449.

Nieuwenhuis, S., Heslenfeld, D.J., von Geusau, N.J., Mars, R.B., Holroyd, C.B., Yeung, N., 2005. Activity in human reward-sensitive brain areas is strongly context dependent. Neuroimage 25, 1302-1309.

Niv, Y., Schoenbaum, G., 2008. Dialogues on prediction errors. Trends Cogn Sci 12, 265272.

Noonan, M.P., Kolling, N., Walton, M.E., Rushworth, M.F., 2012. Re-evaluating the role of the orbitofrontal cortex in reward and reinforcement. Eur J Neurosci 35, 997-1010.

O'Doherty, J., Critchley, H., Deichmann, R., Dolan, R.J., 2003. Dissociating valence of outcome from behavioral control in human orbital and ventral prefrontal cortices. J Neurosci 23, 7931-7939.

O'Doherty, J., Dayan, P., Schultz, J., Deichmann, R., Friston, K., Dolan, R.J., 2004. Dissociable roles of ventral and dorsal striatum in instrumental conditioning. Science 304, 452-454.

O'Doherty, J., Kringelbach, M.L., Rolls, E.T., Hornak, J., Andrews, C., 2001a. Abstract reward and punishment representations in the human orbitofrontal cortex. Nat Neurosci 4, 95-102.

O'Doherty, J., Rolls, E.T., Francis, S., Bowtell, R., McGlone, F., 2001b. Representation of pleasant and aversive taste in the human brain. J Neurophysiol 85, 1315-1321.

O'Doherty, J., Rolls, E.T., Francis, S., Bowtell, R., McGlone, F., Kobal, G., Renner, B., Ahne, G., 2000. Sensory-specific satiety-related olfactory activation of the human orbitofrontal cortex. Neuroreport 11, 893-897.

O'Doherty, J.P., 2004. Reward representations and reward-related learning in the human brain: insights from neuroimaging. Curr Opin Neurobiol 14, 769-776.

O'Doherty, J.P., 2007. Lights, camembert, action! The role of human orbitofrontal cortex in encoding stimuli, rewards, and choices. Ann N Y Acad Sci 1121, 254-272.

O'Doherty, J.P., Deichmann, R., Critchley, H.D., Dolan, R.J., 2002. Neural responses during anticipation of a primary taste reward. Neuron 33, 815-826.

Ongür, D., Price, J.L., 2000. The organization of networks within the orbital and medial prefrontal cortex of rats, monkeys and humans. Cereb Cortex 10, 206-219. 
Padoa-Schioppa, C., Assad, J.A., 2008. The representation of economic value in the orbitofrontal cortex is invariant for changes of menu. Nat Neurosci 11, 95-102.

Paton, J.J., Belova, M.A., Morrison, S.E., Salzman, C.D., 2006. The primate amygdala represents the positive and negative value of visual stimuli during learning. Nature 439, 865-870.

Paul, T., Schiffer, B., Zwarg, T., Kruger, T.H., Karama, S., Schedlowski, M., Forsting, M., Gizewski, E.R., 2008. Brain response to visual sexual stimuli in heterosexual and homosexual males. Hum Brain Mapp 29, 726-735.

Paulus, M.P., Stein, M.B., 2006. An insular view of anxiety. Biol Psychiatry 60, 383-387.

Peters, J., Buchel, C., 2010. Neural representations of subjective reward value. Behav Brain Res 213, 135-141.

Petrovic, P., Kalisch, R., Pessiglione, M., Singer, T., Dolan, R.J., 2008a. Learning affective values for faces is expressed in amygdala and fusiform gyrus. Soc Cogn Affect Neurosci 3, 109-118.

Petrovic, P., Pleger, B., Seymour, B., Kloppel, S., De Martino, B., Critchley, H., Dolan, R.J., 2008b. Blocking central opiate function modulates hedonic impact and anterior cingulate response to rewards and losses. J Neurosci 28, 10509-10516.

Plassmann, H., O'Doherty, J., Rangel, A., 2007. Orbitofrontal cortex encodes willingness to pay in everyday economic transactions. J Neurosci 27, 9984-9988.

Plassmann, H., O'Doherty, J., Shiv, B., Rangel, A., 2008. Marketing actions can modulate neural representations of experienced pleasantness. Proc Natl Acad Sci U S A 105, 1050-1054.

Poldrack, R.A., 2008. The role of fMRI in cognitive neuroscience: where do we stand? Curr Opin Neurobiol 18, 223-227.

Ponseti, J., Bosinski, H.A., Wolff, S., Peller, M., Jansen, O., Mehdorn, H.M., Buchel, C., Siebner, H.R., 2006. A functional endophenotype for sexual orientation in humans. Neuroimage 33, 825-833.

Preuschoff, K., Quartz, S.R., Bossaerts, P., 2008. Human insula activation reflects risk prediction errors as well as risk. J Neurosci 28, 2745-2752.

Prevost, C., McCabe, J.A., Jessup, R.K., Bossaerts, P., O'Doherty, J.P., 2011. Differentiable contributions of human amygdalar subregions in the computations underlying reward and avoidance learning. Eur J Neurosci 34, 134-145.

Prévost, C., Pessiglione, M., Metereau, E., Cléry-Melin, M.L., Dreher, J.C., 2010. Distinct valuation subsystems in the human brain for effort and delay. J Neurosci 30, 1408014090.

Rademacher, L., Krach, S., Kohls, G., Irmak, A., Grunder, G., Spreckelmeyer, K.N., 2010. Dissociation of neural networks for anticipation and consumption of monetary and social rewards. Neuroimage 49, 3276-3285.

Ramnani, N., Elliott, R., Athwal, B.S., Passingham, R.E., 2004. Prediction error for free monetary reward in the human prefrontal cortex. Neuroimage 23, 777-786.

Rangel, A., Hare, T., 2010. Neural computations associated with goal-directed choice. Curr Opin Neurobiol 20, 262-270.

Redouté, J., Stoleru, S., Gregoire, M.C., Costes, N., Cinotti, L., Lavenne, F., Le Bars, D., Forest, M.G., Pujol, J.F., 2000. Brain processing of visual sexual stimuli in human males. Hum Brain Mapp 11, 162-177.

Reuter, J., Raedler, T., Rose, M., Hand, I., Glascher, J., Buchel, C., 2005. Pathological gambling is linked to reduced activation of the mesolimbic reward system. Nat Neurosci 8, 147-148.

Rogers, R.D., Ramnani, N., Mackay, C., Wilson, J.L., Jezzard, P., Carter, C.S., Smith, S.M., 2004. Distinct portions of anterior cingulate cortex and medial prefrontal cortex are 
activated by reward processing in separable phases of decision-making cognition. Biol Psychiatry 55, 594-602.

Rohe, T., Weber, B., Fliessbach, K., 2012. Dissociation of BOLD responses to reward prediction errors and reward receipt by a model comparison. Eur J Neurosci.

Roiser, J.P., Stephan, K.E., den Ouden, H.E., Friston, K.J., Joyce, E.M., 2010. Adaptive and aberrant reward prediction signals in the human brain. Neuroimage 50, 657-664.

Rolls, E.T., 2000. On the brain and emotion. Behavioral and Brain Sciences 23, 219-228.

Rolls, E.T., McCabe, C., 2007. Enhanced affective brain representations of chocolate in cravers vs. non-cravers. Eur J Neurosci 26, 1067-1076.

Rutledge, R.B., Dean, M., Caplin, A., Glimcher, P.W., 2010. Testing the reward prediction error hypothesis with an axiomatic model. J Neurosci 30, 13525-13536.

Sabatinelli, D., Bradley, M.M., Lang, P.J., Costa, V.D., Versace, F., 2007. Pleasure rather than salience activates human nucleus accumbens and medial prefrontal cortex. $\mathrm{J}$ Neurophysiol 98, 1374-1379.

Safron, A., Barch, B., Bailey, J.M., Gitelman, D.R., Parrish, T.B., Reber, P.J., 2007. Neural correlates of sexual arousal in homosexual and heterosexual men. Behav Neurosci 121, 237-248.

Salimi-Khorshidi, G., Smith, S.M., Keltner, J.R., Wager, T.D., Nichols, T.E., 2009. Metaanalysis of neuroimaging data: a comparison of image-based and coordinate-based pooling of studies. Neuroimage 45, 810-823.

Samanez-Larkin, G.R., Kuhnen, C.M., Yoo, D.J., Knutson, B., 2010. Variability in nucleus accumbens activity mediates age-related suboptimal financial risk taking. J Neurosci 30, 1426-1434.

Schiffer, B., Paul, T., Gizewski, E., Forsting, M., Leygraf, N., Schedlowski, M., Kruger, T.H., 2008. Functional brain correlates of heterosexual paedophilia. Neuroimage 41, 80-91.

Schultz, W., 2000. Multiple reward signals in the brain. Nat Rev Neurosci 1, 199-207.

Schultz, W., 2006. Behavioral theories and the neurophysiology of reward. Annu Rev Psychol 57, 87-115.

Seo, Y., Jeong, B., Kim, J.W., Choi, J., 2010. The relationship between age and brain response to visual erotic stimuli in healthy heterosexual males. Int $\mathrm{J}$ Impot Res 22, 234-239.

Sescousse, G., Redouté, J., Dreher, J.C., 2010. The architecture of reward value coding in the orbitofrontal cortex. J Neurosci 30, 13095-13104.

Singer, T., Critchley, H.D., Preuschoff, K., 2009. A common role of insula in feelings, empathy and uncertainty. Trends Cogn Sci 13, 334-340.

Small, D.M., Gregory, M.D., Mak, Y.E., Gitelman, D., Mesulam, M.M., Parrish, T., 2003. Dissociation of neural representation of intensity and affective valuation in human gustation. Neuron 39, 701-711.

Small, D.M., Veldhuizen, M.G., Felsted, J., Mak, Y.E., McGlone, F., 2008. Separable substrates for anticipatory and consummatory food chemosensation. Neuron 57, 786797.

Small, D.M., Zatorre, R.J., Dagher, A., Evans, A.C., Jones-Gotman, M., 2001. Changes in brain activity related to eating chocolate: from pleasure to aversion. Brain 124, 17201733.

Smith, D.V., Hayden, B.Y., Truong, T.K., Song, A.W., Platt, M.L., Huettel, S.A., 2010. Distinct value signals in anterior and posterior ventromedial prefrontal cortex. $\mathrm{J}$ Neurosci 30, 2490-2495.

Stoleru, S., Fonteille, V., Cornelis, C., Joyal, C., Moulier, V., 2012. Functional neuroimaging studies of sexual arousal and orgasm in healthy men and women: A review and metaanalysis. Neurosci Biobehav Rev 36, 1481-1509. 
Stoleru, S., Gregoire, M.C., Gerard, D., Decety, J., Lafarge, E., Cinotti, L., Lavenne, F., Le Bars, D., Vernet-Maury, E., Rada, H., Collet, C., Mazoyer, B., Forest, M.G., Magnin, F., Spira, A., Comar, D., 1999. Neuroanatomical correlates of visually evoked sexual arousal in human males. Arch Sex Behav 28, 1-21.

Sugase-Miyamoto, Y., Richmond, B.J., 2005. Neuronal signals in the monkey basolateral amygdala during reward schedules. J Neurosci 25, 11071-11083.

Sundaram, T., Jeong, G.W., Kim, T.H., Kim, G.W., Baek, H.S., Kang, H.K., 2010. Timecourse analysis of the neuroanatomical correlates of sexual arousal evoked by erotic video stimuli in healthy males. Korean J Radiol 11, 278-285.

Tricomi, E.M., Delgado, M.R., Fiez, J.A., 2004. Modulation of caudate activity by action contingency. Neuron 41, 281-292.

Turkeltaub, P.E., Eden, G.F., Jones, K.M., Zeffiro, T.A., 2002. Meta-analysis of the functional neuroanatomy of single-word reading: method and validation. Neuroimage 16, 765-780.

Tye, K.M., Janak, P.H., 2007. Amygdala neurons differentially encode motivation and reinforcement. J Neurosci 27, 3937-3945.

Uher, R., Treasure, J., Heining, M., Brammer, M.J., Campbell, I.C., 2006. Cerebral processing of food-related stimuli: effects of fasting and gender. Behav Brain Res 169, 111-119.

Van Leijenhorst, L., Zanolie, K., Van Meel, C.S., Westenberg, P.M., Rombouts, S.A., Crone, E.A., 2010. What motivates the adolescent? Brain regions mediating reward sensitivity across adolescence. Cereb Cortex 20, 61-69.

Veldhuizen, M.G., Douglas, D., Aschenbrenner, K., Gitelman, D.R., Small, D.M., 2011. The anterior insular cortex represents breaches of taste identity expectation. J Neurosci 31, $14735-14744$.

Vollm, B., Richardson, P., McKie, S., Elliott, R., Dolan, M., Deakin, B., 2007. Neuronal correlates of reward and loss in Cluster B personality disorders: a functional magnetic resonance imaging study. Psychiatry Res 156, 151-167.

Wager, T.D., Lindquist, M.A., Nichols, T.E., Kober, H., Van Snellenberg, J.X., 2009. Evaluating the consistency and specificity of neuroimaging data using meta-analysis. Neuroimage 45, S210-221.

Walter, M., Bermpohl, F., Mouras, H., Schiltz, K., Tempelmann, C., Rotte, M., Heinze, H.J., Bogerts, B., Northoff, G., 2008. Distinguishing specific sexual and general emotional effects in fMRI-subcortical and cortical arousal during erotic picture viewing. Neuroimage 40, 1482-1494.

Wang, G.J., Volkow, N.D., Telang, F., Jayne, M., Ma, Y., Pradhan, K., Zhu, W., Wong, C.T., Thanos, P.K., Geliebter, A., Biegon, A., Fowler, J.S., 2009. Evidence of gender differences in the ability to inhibit brain activation elicited by food stimulation. Proc Natl Acad Sci U S A 106, 1249-1254.

Wise, S.P., 2008. Forward frontal fields: phylogeny and fundamental function. Trends Neurosci 31, 599-608.

Worbe, Y., Baup, N., Grabli, D., Chaigneau, M., Mounayar, S., McCairn, K., Feger, J., Tremblay, L., 2009. Behavioral and movement disorders induced by local inhibitory dysfunction in primate striatum. Cereb Cortex 19, 1844-1856.

Yacubian, J., Glascher, J., Schroeder, K., Sommer, T., Braus, D.F., Buchel, C., 2006. Dissociable systems for gain- and loss-related value predictions and errors of prediction in the human brain. J Neurosci 26, 9530-9537.

Yarkoni, T., Poldrack, R.A., Nichols, T.E., Van Essen, D.C., Wager, T.D., 2011. Large-scale automated synthesis of human functional neuroimaging data. Nat Methods 8, 665-670. 
Yarkoni, T., Poldrack, R.A., Van Essen, D.C., Wager, T.D., 2010. Cognitive neuroscience 2.0: building a cumulative science of human brain function. Trends Cogn Sci 14, 489496.

Zald, D.H., 2003. The human amygdala and the emotional evaluation of sensory stimuli. Brain Res Brain Res Rev 41, 88-123.

Zald, D.H., Hagen, M.C., Pardo, J.V., 2002. Neural correlates of tasting concentrated quinine and sugar solutions. J Neurophysiol 87, 1068-1075.

Zald, D.H., Lee, J.T., Fluegel, K.W., Pardo, J.V., 1998. Aversive gustatory stimulation activates limbic circuits in humans. Brain 121 ( Pt 6), 1143-1154.

Zald, D.H., Pardo, J.V., 2000. Cortical activation induced by intraoral stimulation with water in humans. Chem Senses 25, 267-275.

Zink, C.F., Pagnoni, G., Martin-Skurski, M.E., Chappelow, J.C., Berns, G.S., 2004. Human striatal responses to monetary reward depend on saliency. Neuron 42, 509-517.

Zink, C.F., Tong, Y., Chen, Q., Bassett, D.S., Stein, J.L., Meyer-Lindenberg, A., 2008. Know your place: neural processing of social hierarchy in humans. Neuron 58, 273-283. 


\section{Figure captions}

Fig. 1. "Common reward circuit" as defined by the overlap of ALE maps produced by monetary, food and erotic reward studies. The ALE maps in the three leftmost columns show the brain regions consistently and commonly activated by monetary, erotic and food reward outcomes. The colour scale indicates the magnitude of ALE values, i.e. the degree of consistency across studies. The maps on the right illustrate the overlap of activation clusters across rewards (green = monetary rewards, red = erotic rewards, blue $=$ food rewards). The ALE maps are overlaid on the Colin brain provided with GingerALE $(p<0.01$ FDR whole-brain corrected and cluster size $>600 \mathrm{~mm}^{3}$ ).

Fig. 2. Brain regions more reliably activated by one reward compared to the other two (i.e. "reward type-specific"). These regions result from contrasts between the different meta-analyses: "money-specific" regions (green) result from the conjunction of money>erotic and money>food maps, "erotic-specific" regions (red) result from the conjunction of erotic>money and erotic>food maps, and "food-specific" regions (blue) result from the conjunction of food>money and food>erotic maps. "Primary reward-specific" regions (purple) result from the conjunction of erotic $>$ money and food>money maps. The ALE maps are overlaid on the Colin brain provided with GingerALE ( $p<0.05$ FDR whole-brain corrected and cluster size $>600 \mathrm{~mm}^{3}$; except for the primary reward-specific activation in the left insula: $\mathrm{p}<0.05$ FDR whole-brain corrected and cluster size $=350 \mathrm{~mm}^{3}$ ).

Fig. 3. Overview of the brain regions involved in reward outcome processing as a function of reward type. (A) "Common reward circuit", i.e. the brain responding to monetary, erotic and food rewards. The putative main functional role assigned to each region is mentioned in italics. Rewards eliciting a particularly robust activation in certain regions are mentioned in square brackets. (B) Reward type-specific regions, i.e. more reliably activated by one reward compared to the other two. The putative main functional role assigned to each region is mentioned in italics. Green: "money-specific" regions, Red: "erotic-specific" regions, Blue: "food-specific" regions, Fuchsia: "primary reward-specific". 
Tables

\begin{tabular}{|c|c|c|c|c|c|c|}
\hline Study & Modality & $\mathbf{n}$ & Foci & Task & Contrast & Statistical threshold \\
\hline (Abler et al., 2007) & fMRI & 8 & 9 & Monetary Incentive Delay task (modified) & Monetary gain > Omission & $p<0.001$ voxel-level uncorr $\& k \geq 10$ \\
\hline (Bjork et al., 2004) & fMRI & 12 & 15 & Monetary Incentive Delay task & Monetary gain > Omission & $p<0.0001 \mid p<0.00001$ voxel-level uncorr \\
\hline (Bjork et al., 2008) & fMRI & 23 & 2 & Monetary Incentive Delay task & Monetary gain > Omission & $p<0.001$ voxel-level uncorr $\& p<0.05$ cluster-level corr \\
\hline (Bjork et al., 2010) & fMRI & 24 & 6 & Monetary Incentive Delay task & Monetary gain > Omission & $\mathrm{p}<0.05$ voxel-level FDR corr \\
\hline (Camara et al., 2008) & fMRI & 17 & 18 & Number guessing task & Monetary gain > Baseline & $p<0.0001$ voxel-level uncorr $\& p<0.05$ cluster-level corr \\
\hline (Clark et al., 2009) & fMRI & 15 & 18 & Slot machine gambling task & Monetary gain > Omission & $p<0.05$ voxel-level FWE corr \\
\hline (Cox et al., 2005) & fMRI & 22 & 28 & Card guessing task & Monetary gain > Loss & $p<0.05$ voxel-level corr (permutation testing) \\
\hline (Elliott et al., 2000) & fMRI & 9 & 2 & Card guessing task & $\begin{array}{l}\text { Positive correlation with cumulative } \\
\text { reward level }\end{array}$ & $p<0.001$ voxel-level uncorr $\mid p<0.05$ corr \\
\hline (Elliott et al., 2003) & fMRI & 12 & 11 & Target detection task & Monetary gain > Baseline & $p<0.001$ voxel-level uncorr $\mid p<0.05$ corr \\
\hline (Elliott et al., 2004) & fMRI & 12 & 10 & Target detection task & Monetary gain > Non-gain & $p<0.001$ voxel-level uncorr $\mid p<0.05$ corr \\
\hline (Ernst et al., 2005) & fMRI & 14 & 16 & Wheel of fortune gambling task & Monetary gain > Omission & $p<0.001$ voxel-level uncorr \\
\hline (Fujiwara et al., 2009) & fMRI & 17 & 18 & Card guessing task & $\begin{array}{l}\text { Positive correlation with gain }> \\
\text { Positive correlation with loss }\end{array}$ & $p<0.001 \mid p<0.0001$ voxel-level uncorr \\
\hline (Hardin et al., 2009) & fMRI & 18 & 7 & Wheel of fortune gambling task & $\begin{array}{l}\text { (Gain > Gain omission) }>\text { (Loss } \\
\text { omission > Loss) }\end{array}$ & $p<0.00001$ voxel-level uncorr \\
\hline (Izuma et al., 2008) & fMRI & 19 & 23 & Card guessing task & High monetary gain > Non-gain & $p<0.005$ voxel-level uncorr $\& p<0.05$ cluster-level corr \\
\hline (Knutson et al., 2001) & fMRI & 9 & 6 & Monetary Incentive Delay task & Monetary gain > Omission & $p<0.0001$ voxel-level uncorr \\
\hline (Knutson et al., 2003) & fMRI & 12 & 4 & Monetary Incentive Delay task & Monetary gain > Omission & $p<0.0001$ voxel-level uncorr \\
\hline (Knutson et al., 2008) & fMRI & 12 & 15 & Monetary Incentive Delay task & Monetary gain > Omission & $p<0.0001$ voxel-level uncorr $\& k \geq 4$ \\
\hline (Kunig et al., 2000) & PET & 13 & 9 & Pattern recognition task & Monetary gain > Omission & $p<0.001$ voxel-level uncorr \\
\hline (Linke et al., 2010) & fMRI & 33 & 16 & Reversal learning task & Monetary gain $>$ Loss & $p<0.05$ voxel-level FDR corr \\
\hline (Martin et al., 2009) & fMRI & 20 & 2 & Classical conditioning task & Monetary gain > Omission & $p<0.003$ voxel-level uncorr $\& p<0.05$ cluster-level corr \\
\hline (Martin-Solch et al., 2001) & PET & 12 & 41 & Pattern recognition task & Monetary gain > Omission & $p<0.001$ voxel-level uncorr \\
\hline (Météreau and Dreher, 2012) & fMRI & 20 & 13 & Classical conditioning task & Monetary gain > Omission & $p<0.01$ voxel-level FDR corr \& $k \geq 5$ \\
\hline (Nieuwenhuis et al., 2005) & fMRI & 14 & 10 & Card guessing task & Monetary gain $>$ Loss & $p<0.0005$ voxel-level uncorr $\& k \geq 60$ \\
\hline (O'Doherty et al., 2003) & fMRI & 10 & 7 & Reversal learning task & Monetary gain > Loss & $p<0.001$ voxel-level uncorr \\
\hline (Petrovic et al., 2008b) & fMRI & 13 & 11 & Wheel of fortune gambling task & Monetary gain > Omission & $p<0.001$ voxel-level uncorr $\mid p<0.05$ cluster-level corr \\
\hline (Ramnani et al., 2004) & fMRI & 6 & 6 & Classical conditioning task & $\begin{array}{l}\text { Monetary gain (unexpected) } \\
\text { Omission (expected) }\end{array}$ & $p<0.001$ voxel-level uncorr \\
\hline (Reuter et al., 2005) & fMRI & 12 & 4 & Card guessing task & Monetary gain > Loss & $p<0.001$ voxel-level uncorr \\
\hline (Rogers et al., 2004) & fMRI & 14 & 11 & Wheel of fortune type gambling task & Monetary gain > Loss & Z>2.3 voxel-level uncorr $\& p<0.05$ cluster-level corr \\
\hline (Samanez-Larkin et al., 2010) & fMRI & 54 & 6 & Behavioral Investment Allocation Strategy task & Monetary gain > Loss & $p<0.0001$ voxel-level uncorr $\& k \geq 8$ \\
\hline (Sescousse et al., 2010) & fMRI & 18 & 18 & Monetary Incentive Delay task (modified) & Monetary gain > Non-gain & $p<0.01$ voxel-level FDR corr \& $k \geq 15$ \\
\hline (Smith et al., 2010) & fMRI & 23 & 10 & Passive viewing task & Monetary gain $>$ Loss & $Z>2.3$ voxel-level uncorr $\& p<0.05$ cluster-level corr \\
\hline (Van Leijenhorst et al., 2010) & fMRI & 15 & 3 & Slot machine gambling task & Monetary gain > Loss & $p<0.001$ voxel-level uncorr \\
\hline (Vollm et al., 2007) & fMRI & 14 & 19 & Target detection task & Monetary gain > Non-gain & $p<0.001$ voxel-level uncorr $\& k \geq 10$ \\
\hline
\end{tabular}


Table 1. Overview of the monetary reward studies included in our meta-analysis. For each study, the column " $n$ " indicates the number of participants, the column "Foci" indicates the number of foci included in our meta-analysis, and the column "Task" provides a description of the type of paradigm used. In the column "Contrast", "Omission" refers to a null outcome when a potential gain was expected, "Non-gain" refers to a null outcome when such a null outcome was expected, "Loss" refers to a monetary loss when either a gain or a loss was expected, and "Baseline" refers to any low-level condition such as a fixation cross. When multiple thresholds are reported for one study, "\&" means that these thresholds were applied simultaneously to every foci, while "l" means that these thresholds were applied to different foci. 


\begin{tabular}{|c|c|c|c|c|c|c|}
\hline Study & Modality & $\mathbf{n}$ & Foci & Task & Contrast & Statistical threshold \\
\hline (Asensio et al., 2010) & fMRI & 26 & 15 & Passive viewing during a letter discrimination task & Erotic pictures $>$ Neutral pictures & $p<0.05$ voxel-level FWE corr $\& k \geq 20$ \\
\hline (Barros-Loscertales et al., 2010) & fMRI & 45 & 19 & Passive viewing during a letter discrimination task & Erotic pictures $>$ Neutral pictures & $p<0.001$ voxel-level uncorr $\& k \geq 20$ \\
\hline (Beauregard et al., 2001) & fMRI & 10 & 7 & Passive viewing task & Erotic films $>$ Neutral films & $p<0.005$ corr \\
\hline (Bocher et al., 2001) & PET & 10 & 8 & Passive viewing task & Erotic films $>$ Baseline & $p<0.001$ voxel-level uncorr $\& k \geq 50$ \\
\hline (Brunetti et al., 2008) & fMRI & 18 & 26 & Passive viewing task & Erotic films $>$ Sport films & $p<0.001$ voxel-level uncorr \\
\hline (Buhler et al., 2008) & fMRI & 10 & 14 & Passive viewing task & Erotic pictures $>$ Neutral pictures & $p<0.05$ voxel-level FDR corr \& $k \geq 10$ \\
\hline (Domenech and Dreher, 2008) & fMRI & 14 & 25 & Choice preference task & Erotic pictures > Omission & $p<0.0001$ voxel-level uncorr $\& k \geq 15$ \\
\hline (Ferretti et al., 2005) & fMRI & 10 & 17 & Passive viewing task & Erotic films $>$ Sport films & $p<0.05$ Bonferroni corr \\
\hline (Hamann et al., 2004) & fMRI & 14 & 9 & Passive viewing task & Erotic pictures $>$ Neutral pictures & $p<0.001$ voxel-level uncorr $\& k \geq 5$ \\
\hline (Hu et al., 2008) & fMRI & 10 & 28 & Passive viewing task & Erotic films $>$ Baseline & $p<0.001$ voxel-level uncorr $\& k \geq 10$ \\
\hline (Karama et al., 2002) & fMRI & 20 & 18 & Passive viewing task & Erotic films $>$ Neutral films & $p<0.001$ voxel-level uncorr $\mid p<0.05$ corr \\
\hline (Kim et al., 2006) & fMRI & 10 & 12 & Passive viewing task & Erotic films $>$ Sport films & $p<0.001$ voxel-level uncorr | $p<0.05$ corr \\
\hline (Moulier et al., 2006) & fMRI & 10 & 23 & Passive viewing task & $\begin{array}{l}(\text { Nude }>\text { Dressed women })>(\text { Nude }> \\
\text { Dressed children })\end{array}$ & $p<0.001$ voxel-level uncorr $\mid p<0.05$ corr \\
\hline (Mouras et al., 2008) & fMRI & 8 & 18 & Passive viewing task & Erotic films $>$ Humorous films & $p<0.05$ corr \\
\hline (Paul et al., 2008) & fMRI & 12 & 13 & Passive viewing task & Erotic films $>$ Neutral films & $p<0.001$ voxel-level uncorr $\& k \geq 5$ \\
\hline (Ponseti et al., 2006) & fMRI & 53 & 13 & Passive viewing task & Erotic pictures $>$ Neutral pictures & $p<0.01$ voxel-level uncorr $\& p<0.05$ cluster-level corr \\
\hline (Prévost et al., 2010) & fMRI & 16 & 26 & Delay and effort discounting task & Erotic pictures > Baseline & $p<0.0001$ voxel-level uncorr $\& k \geq 15$ \\
\hline (Redouté et al., 2000) & PET & 9 & 14 & Passive viewing task & Erotic films $>$ Neutral films & $p<0.001$ voxel-level uncorr | $p<0.05$ corr \\
\hline (Sabatinelli et al., 2007) & fMRI & 22 & 18 & Passive viewing task & Erotic pictures $>$ Neutral pictures & $p<0.001$ voxel-level uncorr \\
\hline (Safron et al., 2007) & fMRI & 22 & 15 & Passive viewing task & Erotic pictures > Sport pictures & $p<0.001$ voxel-level uncorr $\& p<0.05$ cluster-level corr \\
\hline (Schiffer et al., 2008) & fMRI & 12 & 39 & Passive viewing task & Erotic pictures $>$ Neutral pictures & $p<0.05$ voxel-level FDR corr $\& k \geq 10$ \\
\hline (Seo et al., 2010) & fMRI & 21 & 24 & Passive viewing task & Erotic pictures $>$ Happy faces pictures & Z>2.3 voxel-level uncorr $\& k \geq 10$ \\
\hline (Sescousse et al., 2010) & fMRI & 18 & 30 & Erotic Incentive Delay task & Erotic pictures $>$ Neutral pictures & $p<0.01$ voxel-level FDR corr \& $k \geq 15$ \\
\hline (Stoleru et al., 1999) & PET & 8 & 4 & Passive viewing task & Erotic films $>$ Neutral films & $p<0.001$ voxel-level uncorr $\mid p<0.05$ corr \\
\hline (Sundaram et al., 2010) & fMRI & 14 & 19 & Passive viewing task & Erotic films $>$ Baseline & $\mathrm{p}<0.05$ (unclear whether corrected or not) \\
\hline (Walter et al., 2008) & fMRI & 21 & 15 & Passive viewing task & Erotic pictures $>$ Neutral pictures & $p<0.001$ voxel-level uncorr $\& k \geq 10$ \\
\hline
\end{tabular}

Table 2. Overview of the erotic reward studies included in our meta-analysis. For each study, the column " $n$ " indicates the number of participants, the column "Foci" indicates the number of foci included in our meta-analysis, and the column "Task" provides a description of the type of paradigm used. In the column "Contrast", "Omission" refers to a null outcome when a potential erotic stimulus was expected, and "Baseline" refers to any low-level condition such as a fixation cross. When multiple thresholds are reported for one study, "\&" means that these thresholds were applied simultaneously to every foci, while "l" means that these thresholds were applied to different foci. 


\begin{tabular}{|c|c|c|c|c|c|c|}
\hline Study & Modality & $\mathbf{n}$ & Foci & Task & Contrast & Statistical threshold \\
\hline (Berns et al., 2001) & fMRI & 25 & 1 & Passive delivery task & Preferred > Nonpreferred (between juice and water) & $p<0.01$ voxel-level uncorr $\& k=17$ \\
\hline (de Araujo et al., 2003) & fMRI & 11 & 8 & Passive delivery task & Sucrose $>$ Tasteless drink & $p<0.001 \mid p<0.0001$ voxel-level uncorr $\mid p<0.05$ corr \\
\hline (Del Parigi et al., 2002) & PET & 44 & 20 & Passive delivery task & Liquid meal formula $>$ Water & $\mathrm{p}<0.005$ voxel-level uncorr \\
\hline (Domenech and Dreher, 2008) & fMRI & 14 & 16 & Choice preference task & Juice $>$ Omission & $p<0.01$ voxel-level FDR corr \\
\hline (Felsted et al., 2010) & fMRI & 40 & 13 & Passive delivery task & Milkshake > Tasteless drink & $p<0.05$ voxel-level FDR corr \\
\hline (Francis et al., 1999) & fMRI & 6 & 8 & Passive delivery task & Glucose > Baseline & $p<0.005$ corr \\
\hline (Grabenhorst et al., 2010b) & fMRI & 14 & 4 & Passive delivery task & $\begin{array}{l}\text { Positive correlation with pleasantness of milkshake } \\
\text { flavor }\end{array}$ & $p<0.001$ voxel-level uncorr $\& k \geq 3$ \\
\hline (Green and Murphy, 2012)* & fMRI & 12 & 37 & Passive delivery task & Saccharin $>$ Water & $p<0.001$ voxel-level uncorr $\& p<0.05$ cluster-level corr \\
\hline (Green and Murphy, 2012) * & fMRI & 12 & 20 & Passive delivery task & Saccharin $>$ Water & $p<0.001$ voxel-level uncorr \& $p<0.05$ cluster-level corr \\
\hline (Haase et al., 2009) & fMRI & 18 & 36 & Passive delivery task & Sucrose $>$ Water & $p<0.0005$ voxel-level uncorr $\& p<0.05$ cluster-level corr \\
\hline (Jacobson et al., 2010) & fMRI & 19 & 17 & Passive delivery task & Sucrose $>$ Water & $p<0.015$ voxel-level uncorr $\& p<0.05$ cluster-level corr \\
\hline (Kringelbach et al., 2003) & fMRI & 9 & 5 & Passive delivery task & Liquid food $>$ Tasteless drink & $\mathrm{p}<0.05$ corr \\
\hline (McCabe and Rolls, 2007) & fMRI & 12 & 5 & Passive delivery task & Umami food \& vegetable odor > Tasteless drink & $p<0.001$ voxel-level uncorr $\mid p<0.05$ voxel-level FWE corr \\
\hline (McCabe et al., 2011) & fMRI & 15 & 9 & Passive delivery task & Chocolate $>$ Tasteless drink & $p<0.001$ voxel-level uncorr $\& p<0.05$ cluster-level corr \\
\hline (McClure et al., 2004a) & fMRI & 32 & 1 & Classical conditioning task & Positive correlation with preference for soda drinks & $\mathrm{p}<0.05$ voxel-level FDR corr \\
\hline (Météreau and Dreher, 2012) & fMRI & 20 & 20 & Classical conditioning task & Juice $>$ Omission & $p<0.01$ voxel-level FDR corr \& $k \geq 10$ \\
\hline (O'Doherty et al., 2001b) & fMRI & 7 & 14 & Passive delivery task & Glucose > Tasteless drink & $p<0.01$ voxel-level uncorr in a minimum of 6 of 7 subjects \\
\hline (O'Doherty et al., 2002) & fMRI & 8 & 2 & Classical conditioning task & Glucose > Tasteless drink & $p<0.001$ voxel-level uncorr \\
\hline (Plassmann et al., 2008) & fMRI & 20 & 10 & Passive delivery task & Wine $>$ Tasteless drink & $p<0.001$ voxel-level uncorr $\& k \geq 5$ \\
\hline (Rolls and McCabe, 2007) & fMRI & 16 & 6 & Passive delivery task & Chocolate > Tasteless drink & $p<0.001$ voxel-level uncorr | $p<0.05$ voxel-level FWE corr \\
\hline (Small et al., 2001) & PET & 9 & 18 & Passive delivery task & $\begin{array}{l}\text { Positive correlation with pleasantness ratings for } \\
\text { chocolate }\end{array}$ & $p<0.001$ voxel-level uncorr $\mid p<0.025$ voxel-level FWE corr \\
\hline (Small et al., 2003) & fMRI & 9 & 12 & Passive delivery task & Sucrose $>$ Tasteless drink & $p<0.005$ voxel-level uncorr $\mid p<0.05$ cluster-level corr \\
\hline (Small et al., 2008) & fMRI & 12 & 4 & Passive delivery task & Juice > Tasteless drink & $p<0.001$ voxel-level uncorr \\
\hline (Uher et al., 2006) & fMRI & 8 & 3 & Passive delivery task & Milkshake > Tasteless drink & $p<0.001$ cluster-level corr (permutation testing) \\
\hline (Wang et al., 2009) & PET & 10 & 5 & $\begin{array}{l}\text { Passive delivery task with/without } \\
\text { cognitive inhibition }\end{array}$ & Food $>$ Baseline & unclear ( $p<0.01$ cluster-level corr?) \\
\hline (Zald et al., 1998) & PET & 10 & 3 & Passive delivery task & Chocolate > Water & $p<0.0005$ voxel-level uncorr \\
\hline (Zald and Pardo, 2000) & PET & 23 & 20 & Passive delivery task & Water > Baseline & $p<0.0001$ voxel-level uncorr \\
\hline (Zald et al., 2002) & PET & 9 & 1 & Passive delivery task & Sucrose $>$ Water & $p<0.0005$ voxel-level uncorr \\
\hline
\end{tabular}

Table 3. Overview of the food reward studies included in our meta-analysis. For each study, the column " $n$ " indicates the number of participants, the column "Foci" indicates the number of foci included in our meta-analysis, and the column "Task" provides a description of the type of paradigm used. In the column "Contrast", "Omission" refers to a null outcome when a potential food stimulus was expected, and "Baseline" refers to any low-level condition such as a fixation cross. * The study by Green and Murphy (2012) was split into two studies since results are reported separately for two distinct groups of healthy participants (diet soda drinkers and non-diet soda drinkers). When multiple thresholds are reported for one study, " $\&$ " means that these thresholds were applied simultaneously to every foci, while "|" means that these thresholds were applied to different foci. 


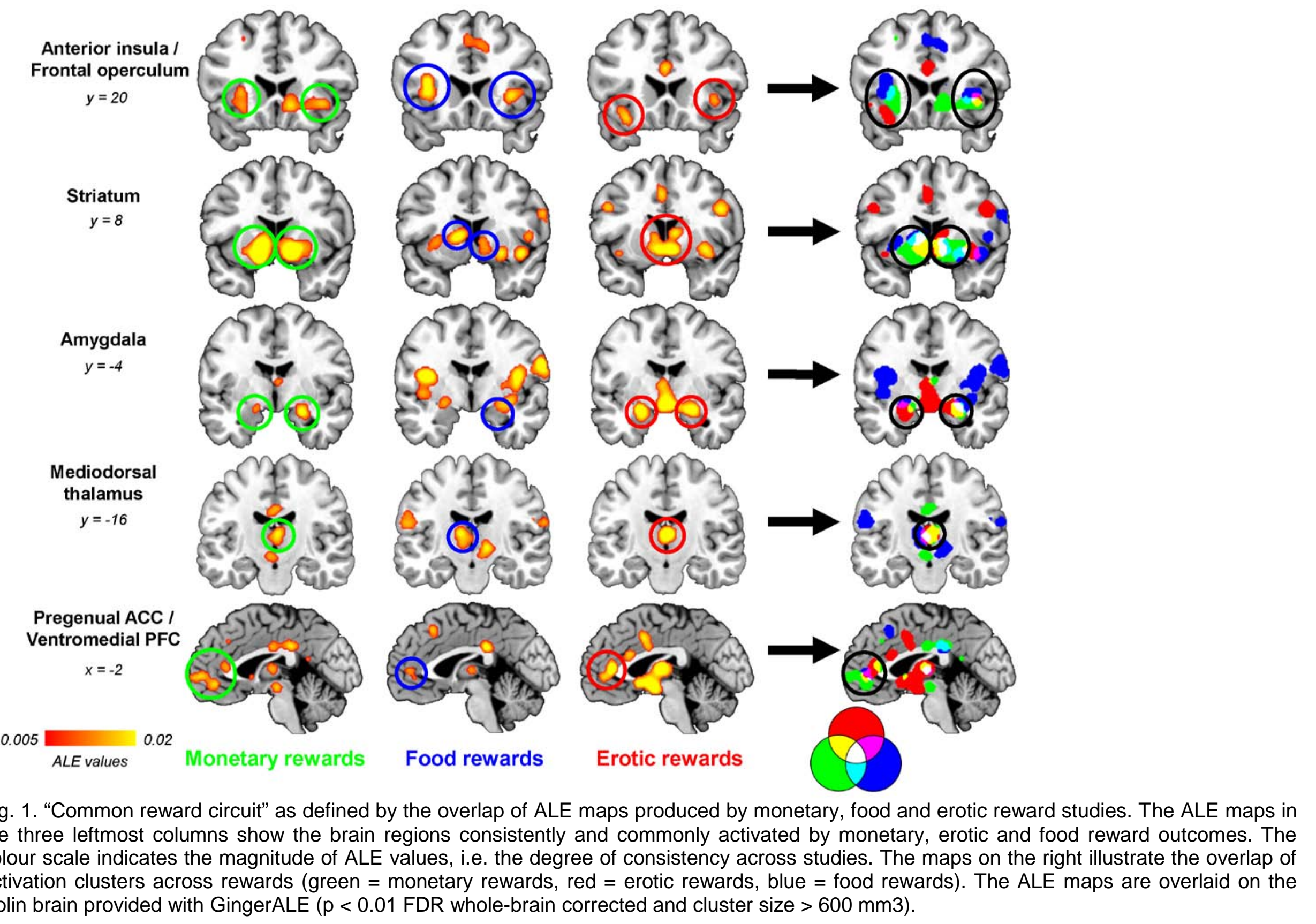




$\begin{array}{ccc}\begin{array}{c}\text { Monetary rewards } \\ \text { (Money }>\text { Erotic }) \cap\end{array} & \text { Erotic rewards } & \text { Food rewards } \\ \text { (Money }>\text { Food }) & (\text { Erotic }>\text { Food) }) & \text { (Food }>\text { Erotic) } \cap \\ \text { (Erotic }>\text { Money) } & \text { (Food }>\text { Money) }\end{array}$

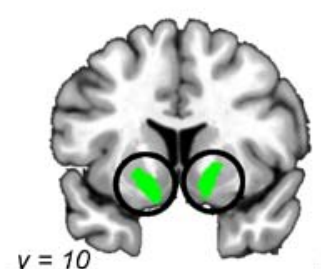

Ventral striatum

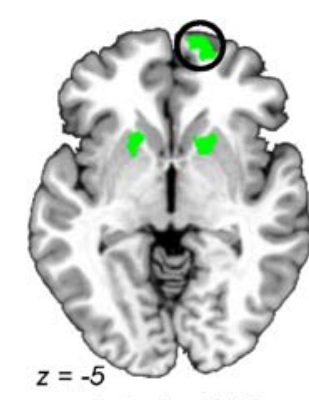

Anterior OFC

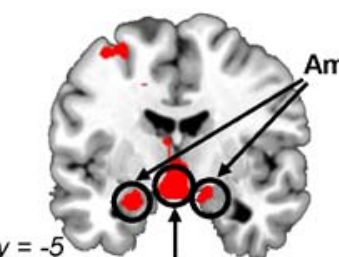

Hypothalamus
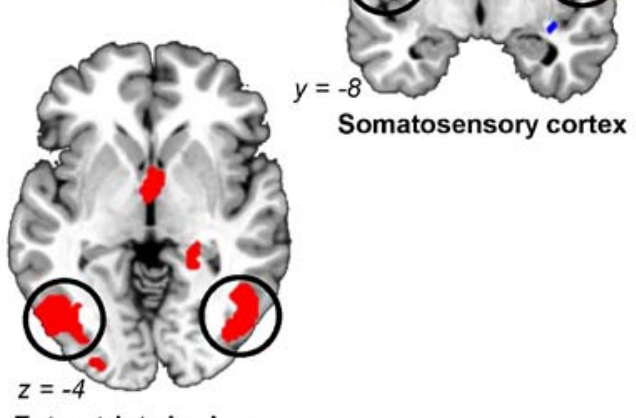

Extrastriate body area
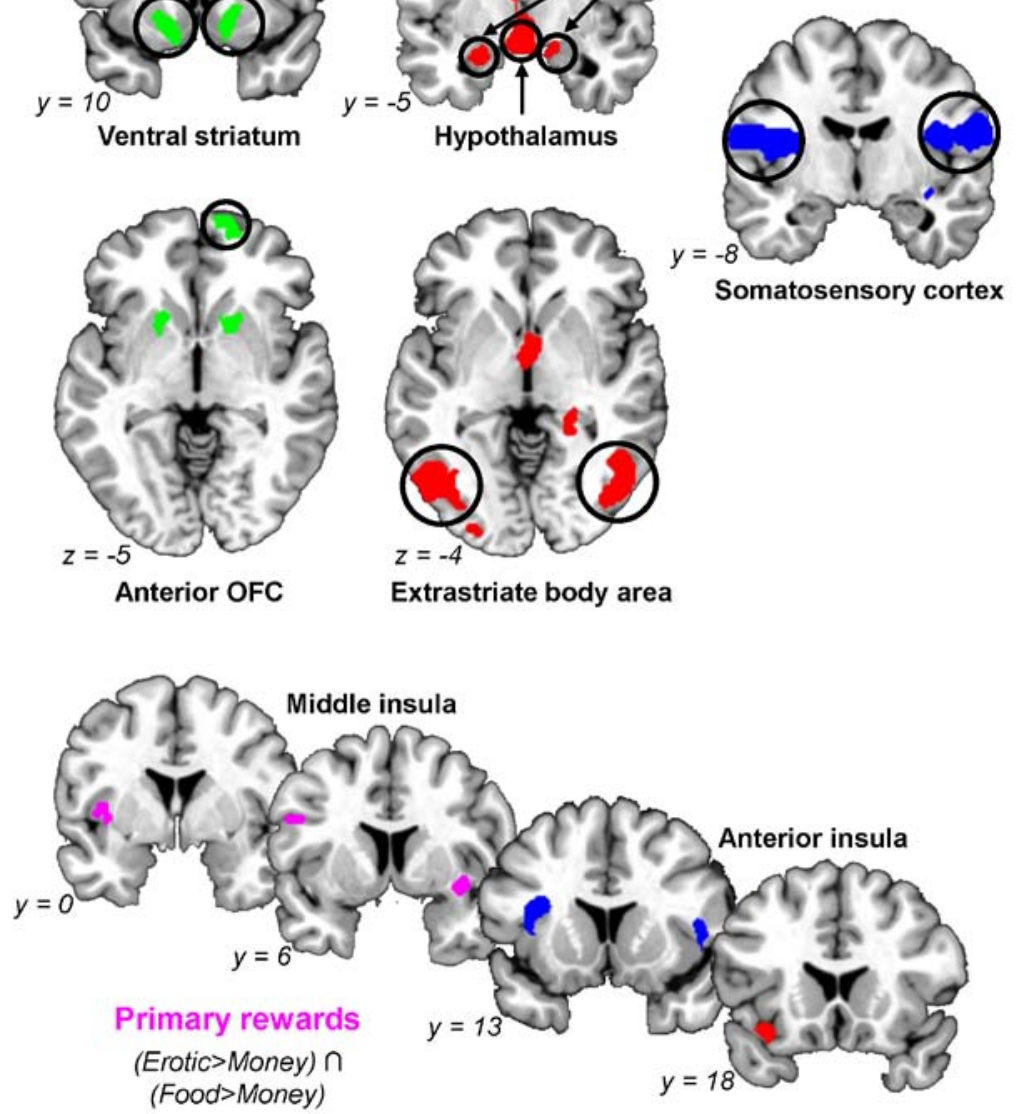

Fig. 2. Brain regions more reliably activated by one reward compared to the other two (i.e. "reward type-specific"). These regions result from contrasts between the different meta-analyses: "money-specific" regions (green) result from the conjunction of money $>$ erotic and money $>$ food maps, "erotic-specific" regions (red) result from the conjunction of erotic > money and erotic > food maps, and "foodspecific" regions (blue) result from the conjunction of food $>$ money and food > erotic maps. "Primary reward-specific" regions (purple) result from the conjunction of erotic $>$ money and food $>$ money maps. The ALE maps are overlaid on the Colin brain provided with GingerALE ( $p<0.05$ FDR whole-brain corrected and cluster size $>600 \mathrm{~mm} 3$; except for the primary reward-specific activation in the left insula: $p<0.05$ FDR whole-brain corrected and cluster size $=350 \mathrm{~mm} 3$ ). 
A

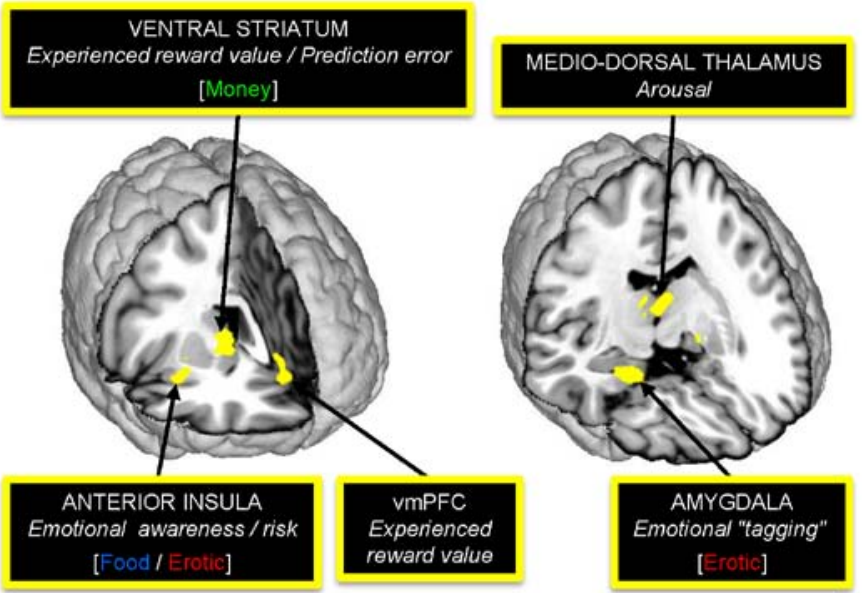

B

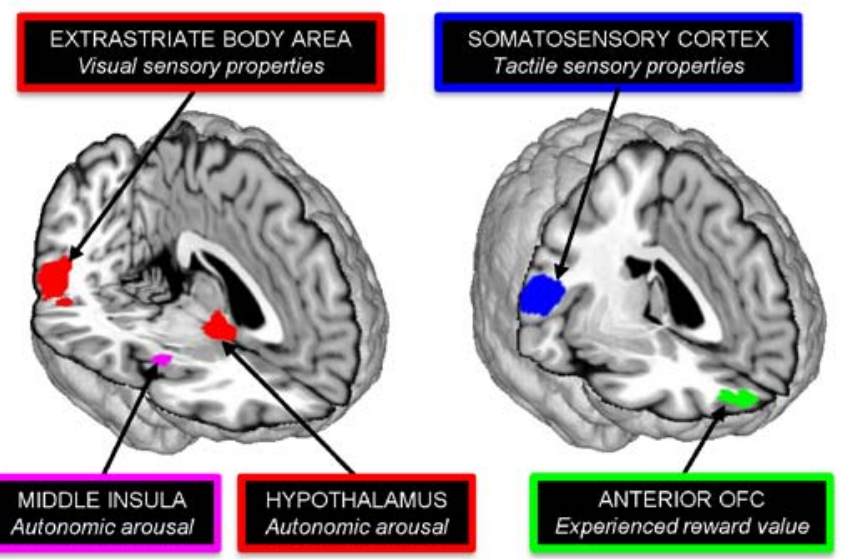

Fig. 3. Overview of the brain regions involved in reward outcome processing as a function of reward type. (A) "Common reward circuit", i.e. the brain responding to monetary, erotic and food rewards. The putative main functional role assigned to each region is mentioned in italics. Rewards eliciting a particularly robust activation in certain regions are mentioned in square brackets. (B) Reward type-specific regions, i.e. more reliably activated by one reward compared to the other two. The putative main functional role assigned to each region is mentioned in italics. Green: "money-specific" regions, Red: "erotic-specific" regions, Blue: "food-specific" regions, Fuchsia: "primary reward-specific". 